\title{
Development of Countermeasures
}

\section{for Driver Maneuver Errors}

PUBLICATION NO. FHWA-RD-00-022

DECEMBER 1999

US. Department of Transportation

Federal Highway Administration

Research, Development, and Technology Turner-Fairbank Highway Research Center 6300 Georgetown Pike

McLean, VA 22101-2296

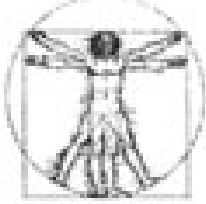




\section{FOREWORD}

This report was produced as part of a contract "Determine Causes of Driver Maneuver Errors," which called for a sequence of analytic and empirical research efforts in order to understand where and when drivers suffer misperceptions that lead to driving maneuver errors. In addition, the contract called for the development of highway safety countermeasures concepts to address those errors. This report presents a brief discussion of the purpose and scope of the project, describes the analytical and empirical activities, and presents the recommended countermeasures developed with the help of an expert panel. The recommended countermeasures merit further evaluation; in most cases, they are not recommended for immediate implementation.

Copies of this report can be obtained through the Research and Technology Report Center, 9701 Philadelphia Court, Unit Q, Lanham, Maryland 20706, telephone: (301) 577-0818, fax: (301) 5771421, or the National Technical Information Service (NTIS), 5285 Port Royal Road, Springfield, Virginia 22161, telephone: (703) 605-6000, fax: (703) 605-6900.

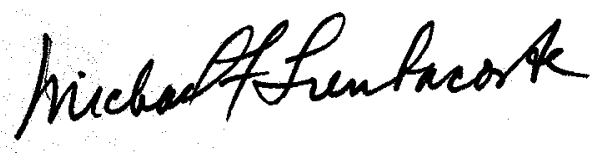

Michael F. Trentacoste, Director, Office of Safety

Research and Development

\section{NOTICE}

This document is disseminated under the sponsorship of the Department of Transportation in the interest of information exchange. The United States Government assumes no liability for its content or use thereof. This report does not constitute a standard, specifications, or regulation.

The United States Government does not endorse products or manufacturers. Trade and manufacturers' names appear in this report only because they are considered essential to the object of the document. 
Technical Report Documentation Page

\begin{tabular}{|l|l|}
$\begin{array}{l}\text { 1. Report No. } \\
\text { FHWA-RD-00-022 }\end{array}$ & 2. Government Accession No \\
\hline 4. Title and Subtitle & \\
DEVELOPMENT OF COUNTERMEASURES FOR DRIVER \\
MANEUVER ERRORS
\end{tabular}
MANEUVER ERRORS

7. Author(s)

Neil D. Lerner, Geoffrey V. Steinberg, and Fred R. Hanscom

9. Performing Organization Name and Address

Westat

1650 Research Boulevard

Rockville, Maryland 20850

11. Contract or Grant No. DTFH61-96-C-00015

12. Sponsoring Agency Name and Address

Office of Safety Research and Development

Federal Highway Administration

6300 Georgetown Pike

McLean, VA 22101-2296

3. Recipient's Catalog No.

5. Report Date

Decęmber 1999

6. Performing Organization Code

8. Performing Organization Report No.

10. Work Unit No. (TRAIS)

NCP No. 3A6A-1162

13. Type of Report and Period Covered

Task D report

3/97-1/99

14. Sponsoring Agency Code

\section{Supplementary Notes}

Contracting Officer's Technical Representative (COTR): M. Joseph Moyer, HRDS; Kate Woerheide, SAIC. We acknowledge the helpful cooperation of Frank Barickman, VRTC, and the National Highway Traffic Safety Administration, for the use of and technical support with the DASCAR instrumented vehicle.

16. Abstract

Drivers may make errors that result in a collision with another vehicle, even when they are aware of the presence of the conflicting vehicle. This is because perceptual judgments about time, space, and speed are imperfect, and can lead to misjudgments about the adequacy of a situation to allow some driving maneuver. Drivers may err in thinking there is more time available for the maneuver than is actually the case; or err in thinking the maneuver takes less time to execute than it actually does. Either misperception could lead to a decision to go ahead with a maneuver with less margin of safety than the driver assumes. Misperceptions of the time available or time required for various driving maneuvers under a range of conditions were studied in this project. In the laboratory experiment, research participants viewed video scenes, filmed from a driver's perspective, of a wide variety of situations. For each scene, the viewers made judgments about when some event would occur (e.g., approaching vehicle reaches them) or when some maneuver would be completed (e.g., own vehicle clears roadway when making a crossing maneuver). Participants' judgments were compared with actual values (for time available) or best estimates from engineering equations and empirical data (for time or distance required). A parallel on-the-road experiment, using similar procedures and a subset of the laboratory situations, was used to validate and benchmark the laboratory findings. The study found a general tendency for people to underestimate the time required to complete a maneuver. Across a range of maneuvers, about 60 percent of all time or distance required judgments were underestimated, relative to engineering and empirical estimates. This misjudgment is safety-critical, because driver perception that a maneuver will take less time than is actually the case may lead to decisions to accept maneuver opportunities that actually afford a smaller margin of error than the driver perceives. Such misestimates were particularly common for judgments of the time to achieve the prevailing traffic speed during turning or merging maneuvers, and for the time until one's vehicle reaches an intersection ahead. For judgments of the time available for a maneuver, the error was usually in a safetyconservative direction. That is, people felt they had less time than they actually did, so would be less likely to attempt a maneuver. However, even for time available judgments, there were meaningful numbers of safety-critical errors (overestimates of time available), especially for estimates of yellow signal phase time remaining and estimates related to a passing scenario. When the combined errors related to both maneuver requirements and availability were jointly considered, some situations emerged as particularly meriting consideration for safety countermeasures. These included: (1) approach to signalized intersections; (2) turns onto higher-speed roadways; (3) freeway merges; (4) passing; and (5) headway maintenance. Following the analysis of the experiment, efforts were undertaken, aided by an expert panel, to develop primarily infrastructure-based countermeasure concepts to address these problems. A number of promising ideas based around roadway design and operations were recommended for formal evaluation.

\section{Key Words}

Driver maneuver errors, safety, research program, human factors, older drivers.

\section{Distribution Statement}

No restrictions. This document is available to the public through the National Technical Information Service, Springfield, Virginia 22161.

\begin{tabular}{c|c}
$\begin{array}{c}\text { 19. Security Classif. (of this report) } \\
\text { Unclassified }\end{array}$ & $\begin{array}{c}\text { 20. Security Classif. (of this page) } \\
\text { Unclassified }\end{array}$ \\
\hline
\end{tabular}
21. No. of Pages 57

22. Price 


\section{Table of Contents}

1.0 INTRODUCTION...................................................................................................................................

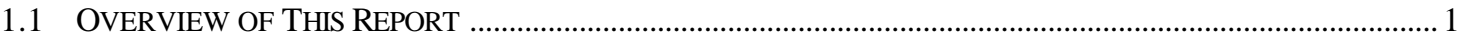

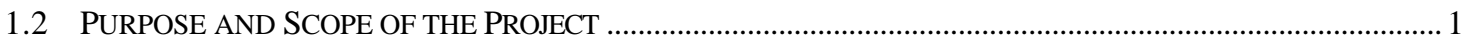

2.0 PREVIOUS TASKS OF THE PROJECT ....................................................................................

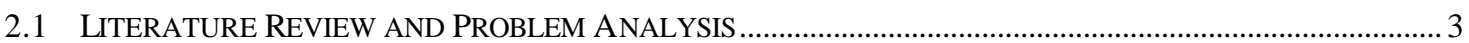

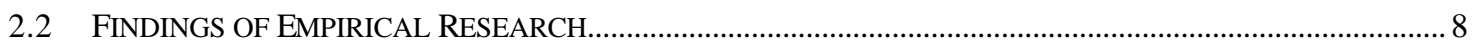

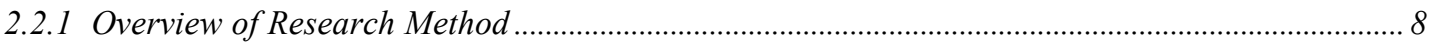

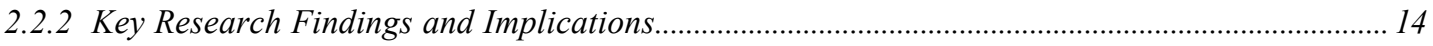

2.3 RECOMMENDED TARGETS FOR COUNTERMEASURE DEVELOPMENT ……………………….................2

3.0 DEVELOPMENT OF COUNTERMEASURES: EXPERT PANEL................................................27

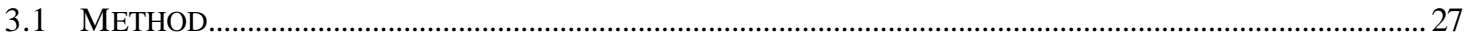

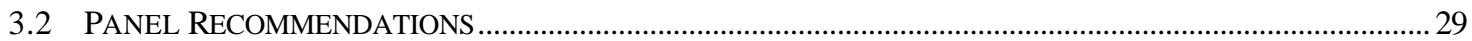

4.0 COUNTERMEASURES RECOMMENDED FOR FUTURE RESEARCH STUDIES .............35

Alternating PASSING LANE GeOMETRICS AND TRAFFiC CONTROL DEVICE TREATMENTS........................... 37

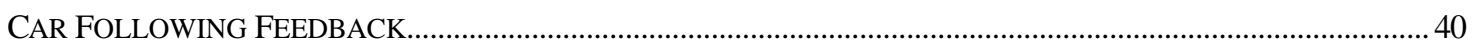

TRAFFIC SIGNAL TIMING TO COMPENSATE FOR DRIVERS' INTERSECTION MISPERCEPTIONS. .......................... 43

HIGHWAY GEOMETRICS AND PAVEMENT MARKINGS TO AID ENTERING TRAFFIC AT INTERSECTIONS ....... 46

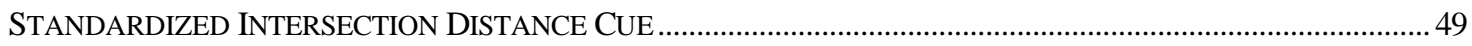

CONFLICTING VEHICLE W ARNINGS AT NON-SIGNALIZED INTERSECTIONS...................................................51

HIGH SPEED APPROACHING VEHICLE W ARNINGS AT INTERSECTIONS............................................................5

5.0 REFERENCES .......................................................................................................................................................56

APPENDIX A. EXPERT PANEL ATTENDEES .........................................................................................57 


\section{List of Figures}

Figure 2-1. Sequence of activities for defining scenarios. .................................................

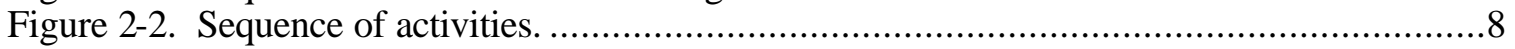

Figure 2-3. Instrumented vehicle components............................................................. 13

Figure 2-4. Time available scenarios, interquartile box plots of distribution of

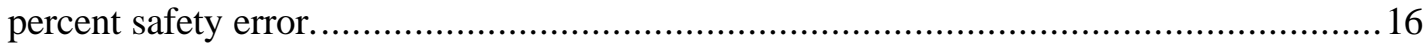

Figure 2-5. Time required scenarios, interquartile box plots of distribution of

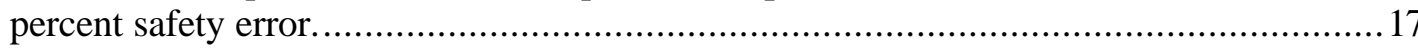

Figure 2-6. Headway distance required scenarios, interquartile box plots of

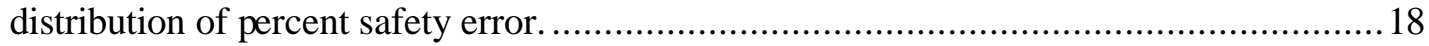

Figure 2-7. Stopping distance required scenarios, interquartile box plots of distribution of percent safety error.

Figure 2-8. Combined scenarios, interquartile box plots of distribution of net percent safety error. 


\section{List of Tables}

Table 2-1. Relation of crash types to maneuvers...........................................................

Table 2-2. Scenarios selected for inclusion in lab and on-road studies. .................................. 10

Table 3-1. General categories of countermeasures for consideration .................................29

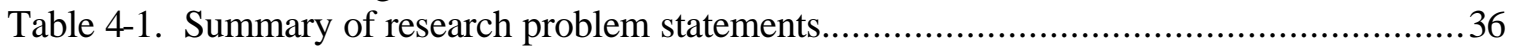




\section{DEVELOPMENT OF COUNTERMEASURES FOR DRIVER MANEUVER ERRORS}

\subsection{Introduction}

\subsection{Overview of This Report}

This report describes the findings of Task D, "Develop Countermeasures," of Project DTFH6196-C-00015, "Determine Causes of Driver Maneuver Errors." The project calls for a sequence of analytic and empirical research efforts in order to understand where and when drivers suffer misperceptions that lead to driving maneuver errors and then the development of highway safety countermeasure concepts to address those errors. The analytic and empirical efforts were completed under Tasks A, B, and C. The present task, Task D, uses the findings of these preceding tasks in order to identify promising approaches to address the safety implications of driver maneuver errors.

This report begins with a brief discussion of the purpose and scope of the project (Section 1.0). Section 2.0 provides an overview of the preceding tasks. Section 2.1 describes the analytic activities of Tasks A and B, and Section 2.2 summarizes the methods and findings of the empirical research conducted under Task C. Section 3.0 describes how an expert panel approach was used to develop a set of promising countermeasure concepts. Section 4.0 provides a final set of priority countermeasure recommendations, with accompanying research problem statements. The "recommended" countermeasure concepts are recommended in the sense that they merit subsequent formal research and evaluation. They are not necessarily recommended for current implementation. The present project does not have any formal countermeasure research or evaluation component to it, so the recommendations represent promising, but not proven, ideas.

\subsection{Purpose and Scope of the Project}

This study investigated the underlying perceptual problems that lead to driver maneuver errors. It was necessary to define the scope of the problem by differentiating driver maneuver error incidents from collision risk engendered by other factors, such as hazard recognition failure, distraction/inattention, intentional recklessness, impairment, vehicle failure, and so forth. Driver maneuver errors occur when a driver chooses to execute a maneuver at a time or in a manner that leads to an unacceptably high likelihood of collision. The maneuver is in "error" because the driver recognizes the situation but still makes the maneuver, but not because of intentional acceptance of the high risk. The magnitude of the risk is misunderstood, despite awareness of the elements of the situation.

We have distinguished two broad categories of maneuver error situations:

- $\quad$ The driver does not properly understand time/space adequacy for the maneuver

- Time or space available for the maneuver

- Time or space required for the maneuver

- The driver exceeds the vehicle dynamics parameters within which he/she can control the vehicle 
As an example, consider a driver making a passing maneuver on a two lane highway, while another vehicle is approaching. This driver might improperly judge the rate at which the gap between his or her own vehicle and the approaching vehicle is closing. The driver might also misjudge the time/distance needed to overtake the lead vehicle and return to the proper lane. Or, the driver might be unable to control lane placement during the two lane change maneuvers. Any one of these errors could lead to a collision.

The research described here emphasizes those aspects of driver maneuver errors that might best be characterized as perceptual judgments. Planning and executing any driving maneuver involves a range of human information processing activities, ranging from the initial sensory perception through complex decision-making. Failures at any point in the process could result in unsafe driving. The focus of this work is not at either end of this information-processing sequence, but rather at the critical intermediate area where the primary perceptual judgments occur. We begin with the assumptions of adequate perceptual recognition and appropriate motivation/decisionmaking. What we are focusing on are complex time/space judgments, which draw on the perception of dynamic events and the ability to visualize and project planned events. The emphasis is in measuring how well people make these judgments and where significant errors occur. By identifying significant, common errors in judging time/space requirements of key driving maneuvers, major problems can be identified and appropriate safety countermeasures can be considered.

For purposes of clarity, we wish to distinguish between the concepts of maneuvers, driving performance elements, misperceptions, and maneuver errors. "Maneuvers" are discrete elements of the driving task, that may be described in terms of the objective: changing a lane, negotiating a curve, passing another vehicle, and so forth. There is a discrete set of driving performance elements that relate, in varying degrees, to all driving maneuvers. For example, these include gap acceptance, speed selection, and lane placement. In order to evaluate the opportunity to execute a maneuver, a driver must be able to compare the demands of the maneuver with the opportunity afforded by the environment. A driver may make an error in judging either end of this comparison. He or she may misperceive the time or space the traffic and roadway situations afford; for example, an approaching vehicle may be 5 seconds away, but may appear to be 6 seconds away. The driver may also misjudge the performance element aspects of the maneuver, and so under- or over-estimate the time or distance required to execute the complete driving maneuver. We characterize these misperceptions as errors in judging "time/distance available" and as errors in judging "time/distance required." These misperceptions are of interest to the extent they lead a driver to make an inappropriate decision about a maneuver. A "maneuver error" is a decision to make a maneuver that may result in a safety or traffic operational consequence. Under this definition, a driver can make a maneuver error without getting into a collision or causing a disruption of other traffic. For example, consider a driver who has selected an inappropriate following headway. Whether this results in a collision depends upon unpredictable circumstances which may cause the lead vehicle to slow suddenly; however, the potential for the collision is there, and the driver has made the same error, based upon a misperception of his ability, whether the collision ultimately occurs or not. Therefore we view a maneuver error as driving behavior that is likely to cause incidents, collisions, or traffic disruptions. The empirical portion of the project focuses on the perceptual demands that underlie a decision about a given maneuver, and evaluates the perceptual errors that most commonly occur. 


\subsection{Previous Tasks of the Project}

The two initial tasks of this project reviewed the literature concerning driver maneuver errors (Task A) and conducted a number of analytic activities to relate maneuvers, performance elements, and crash outcomes (Task B). These efforts fed into an experimental plan for the empirical research portion of the project, which was conducted under Task C.

\subsection{Literature Review and Problem Analysis}

The methods and findings of the Task A literature review are detailed in a project interim report (Task A Working Paper, COMSIS Corporation \& TRC, 1996). This document reviewed the driver, situational, vehicular, and environmental factors that impact driver maneuver errors. The review focused on driver maneuver errors, as opposed to failures of hazard detection or other safety problems, consistent with the project scope as discussed in Section 1.2.

Although the ultimate focus of the work was on maneuver errors, the literature review was organized around a set of driver performance measures. This organization was selected because related studies in the literature more naturally cluster around these performance measures, and a given performance measure may relate to several maneuvers. The set of seven performance measures was based on the work of Lerner, Benel, and Dekker (1995), which identified a limited set of key performance measures that broadly cover most driving situations. The literature review was structured around the following elements:

- Headway selection

- $\quad$ Speed selection

- Intersection negotiation

- Maneuver time

- Gap acceptance

- Crash avoidance

- $\quad$ Lane placement

For each of these items, a comprehensive review was conducted, organized and presented as follows:

- Introduction (definitions, general background)

- $\quad$ Errors for this performance element

- $\quad$ Consequences of errors

- $\quad$ Driver factors (demographic, perceptual, situational)

- $\quad$ Vehicle factors

- $\quad$ Environmental factors

- Implications of the findings

- Initial consideration of countermeasures for these problems

The review identified a variety of important considerations for each of the performance measures, and also identified a rather extensive set (about 80) of preliminary countermeasure concepts. These preliminary concepts were carried forward for further consideration in subsequent tasks of the project. 
Subsequent to the literature review, a series of analytic efforts took place. These analyses related crash types and outcomes, maneuver types and maneuver errors, and driver performance measures to one another, so that ultimately a set of target maneuvers and situations could be defined for use in the empirical research experiment. This work is detailed in the Task B project interim report (Lerner, Benel, Huey, Hanscom, \& Steinberg, 1996). This sequence of activities is shown in Figure 2-1. A key element of this effort was a matrix relating crash types to maneuvers, reproduced here as Table 2-1. These maneuvers were in turn related to specific performance measures and the most critical of these identified. The situations studied and measures used in the subsequent empirical research experiment reflected the outcome of these analytic efforts.

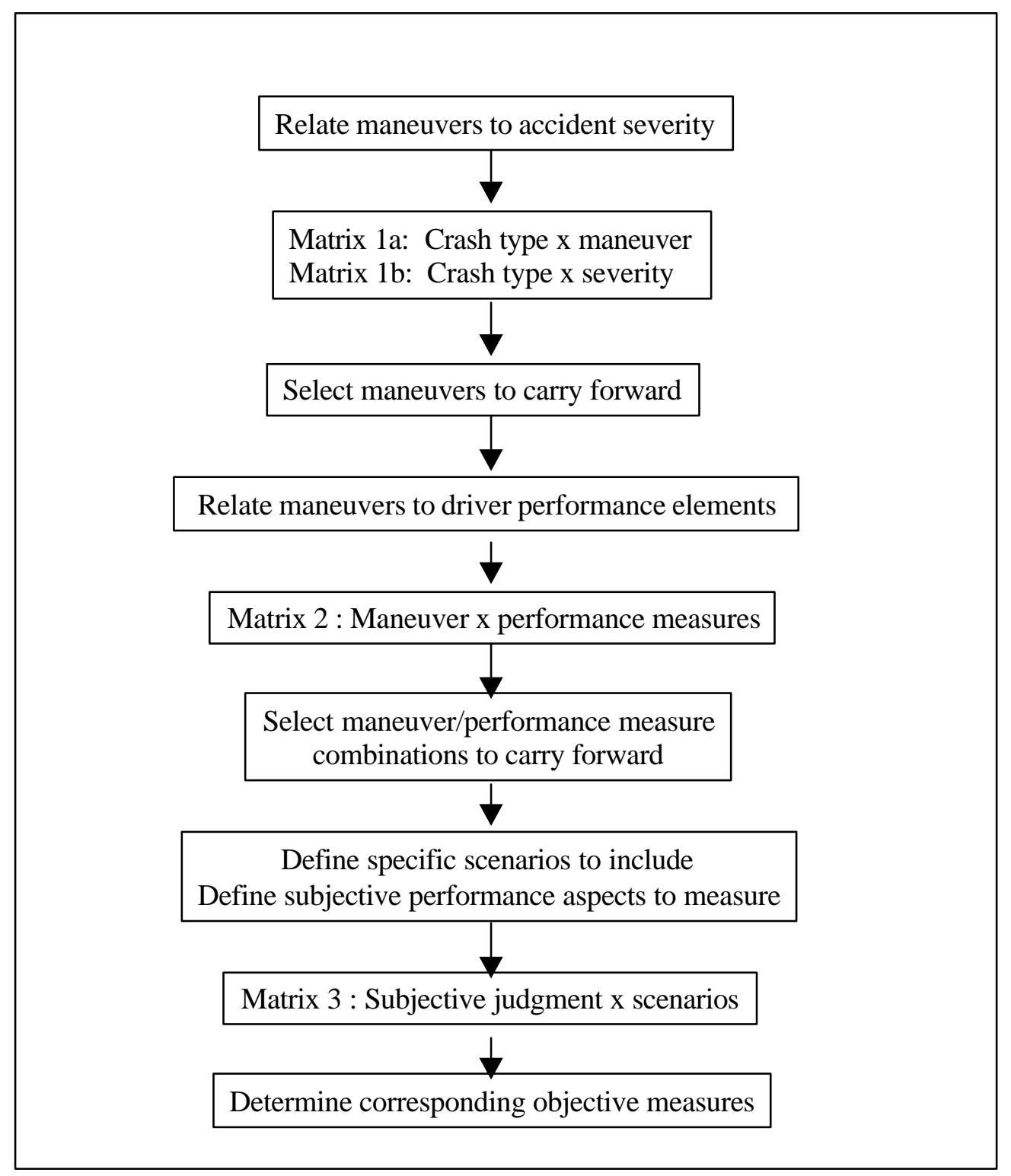

Figure 2-1. Sequence of activities for defining scenarios. 


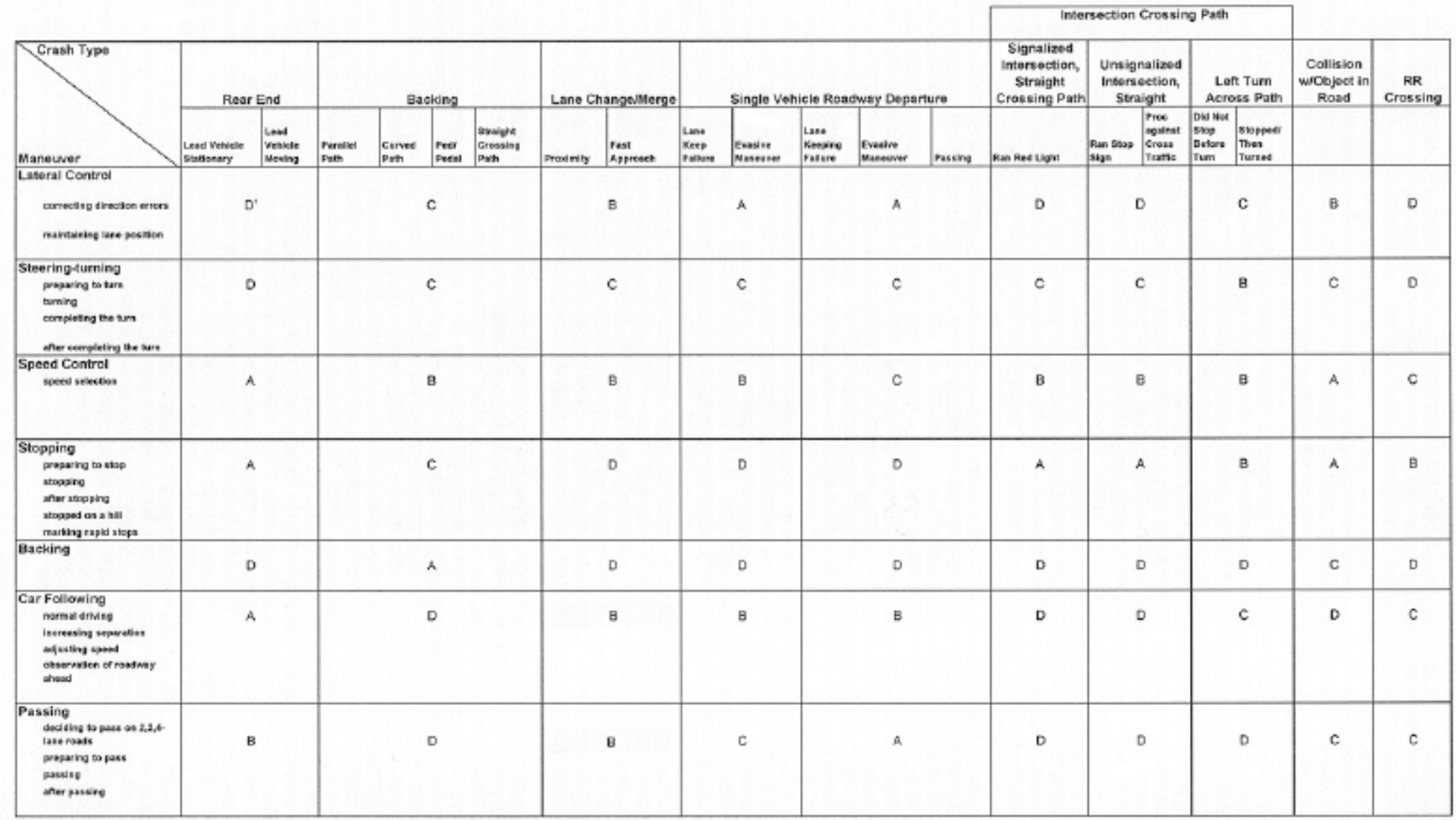

'A = Highiy related

$B=$ Moderetaly related

$C=$ Waakly rolatad
$D=$ Not relsted 


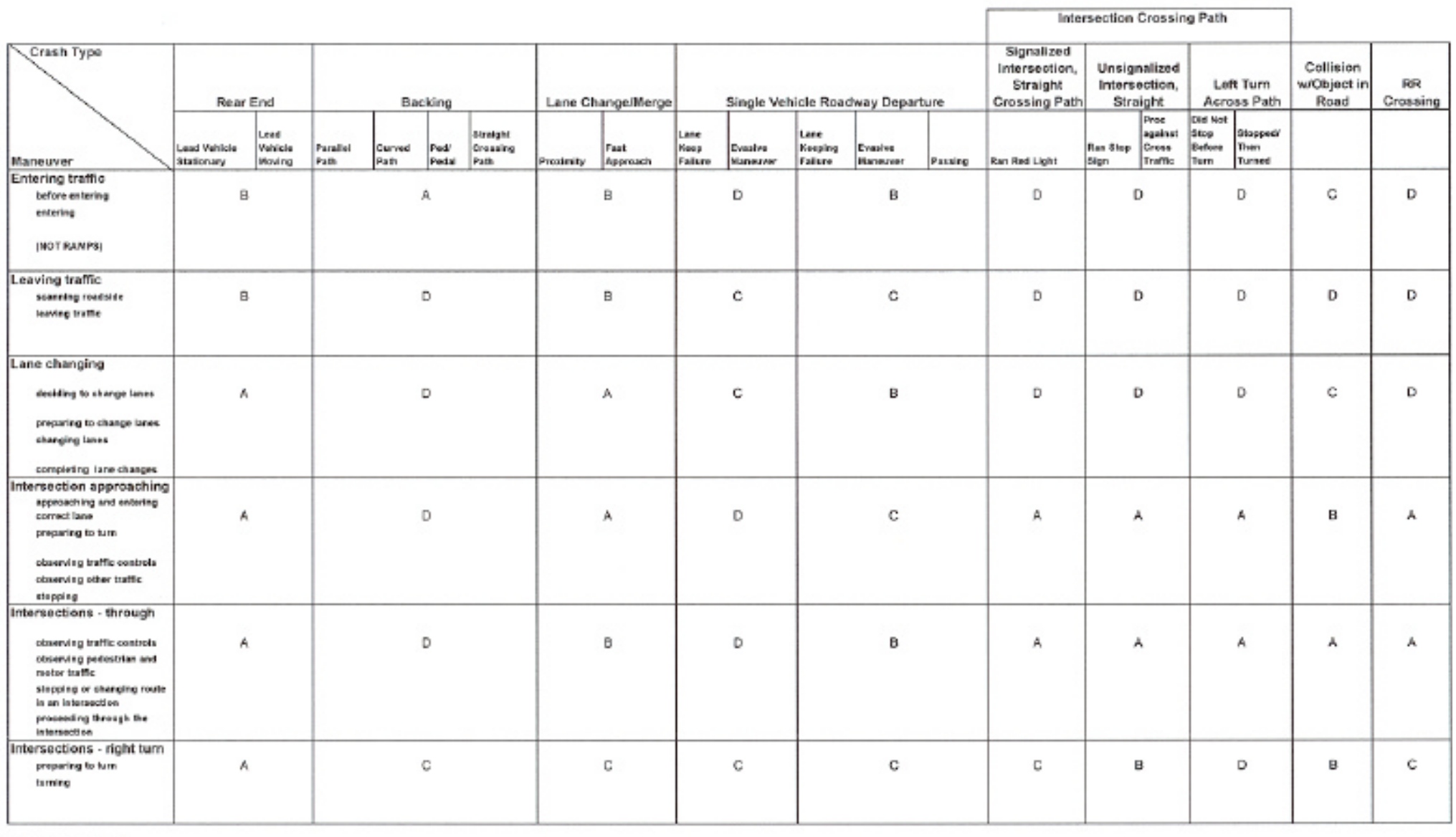

'A = Highly relected

$B=$ Madorataly rotatid

$C=$ Weakly realted

$D=$ Not relaled 


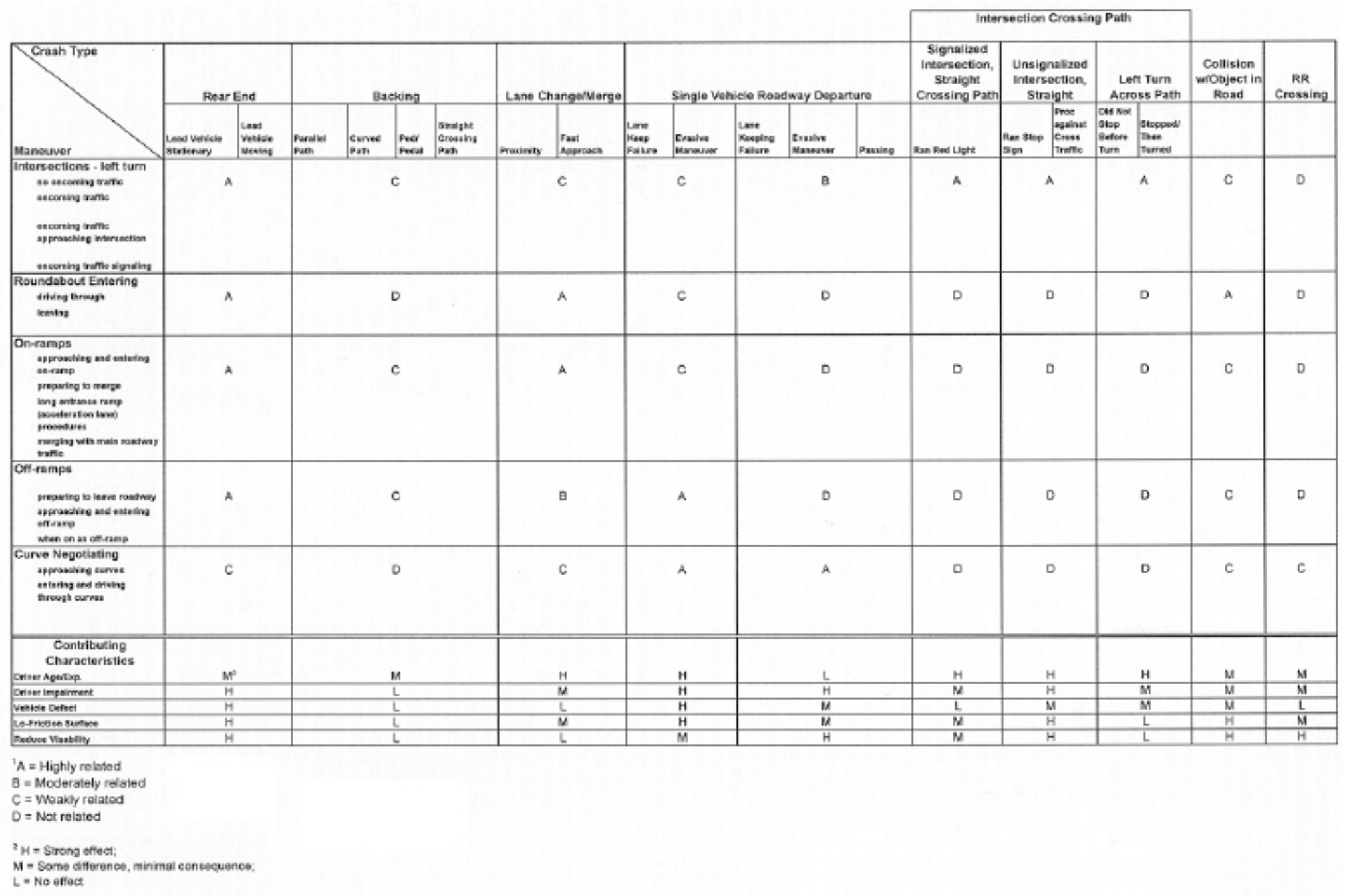




\subsection{Findings of Empirical Research}

This section provides a brief overview of the methods and findings of the empirical research conducted under Task C. A full report may be found in Lerner, Steinberg, Huey, and Hanscom (1998).

\subsubsection{Overview of Research Method}

The experiment had the following specific objectives:

- $\quad$ Determine situations in which drivers misperceive the time available for making a particular driving maneuver;

- $\quad$ Determine situations in which drivers misperceive the time or distance required to make a particular driving maneuver;

- Determine situations in which drivers misperceive the level of hazard associated with making a particular maneuver;

- Identify driver or situational factors that contribute to greater error;

- $\quad$ Relate the findings to the needs for safety countermeasures.

The basic logic of the experiment was to compare people's judgments of time or space in various driving situations with more objective measures of the time or space available or required. Analytical activities in prior project tasks helped define the set of key driving scenarios for inclusion in the experiment. The sequence of activities comprising the empirical research portion of the project is shown schematically in Figure 2-1.

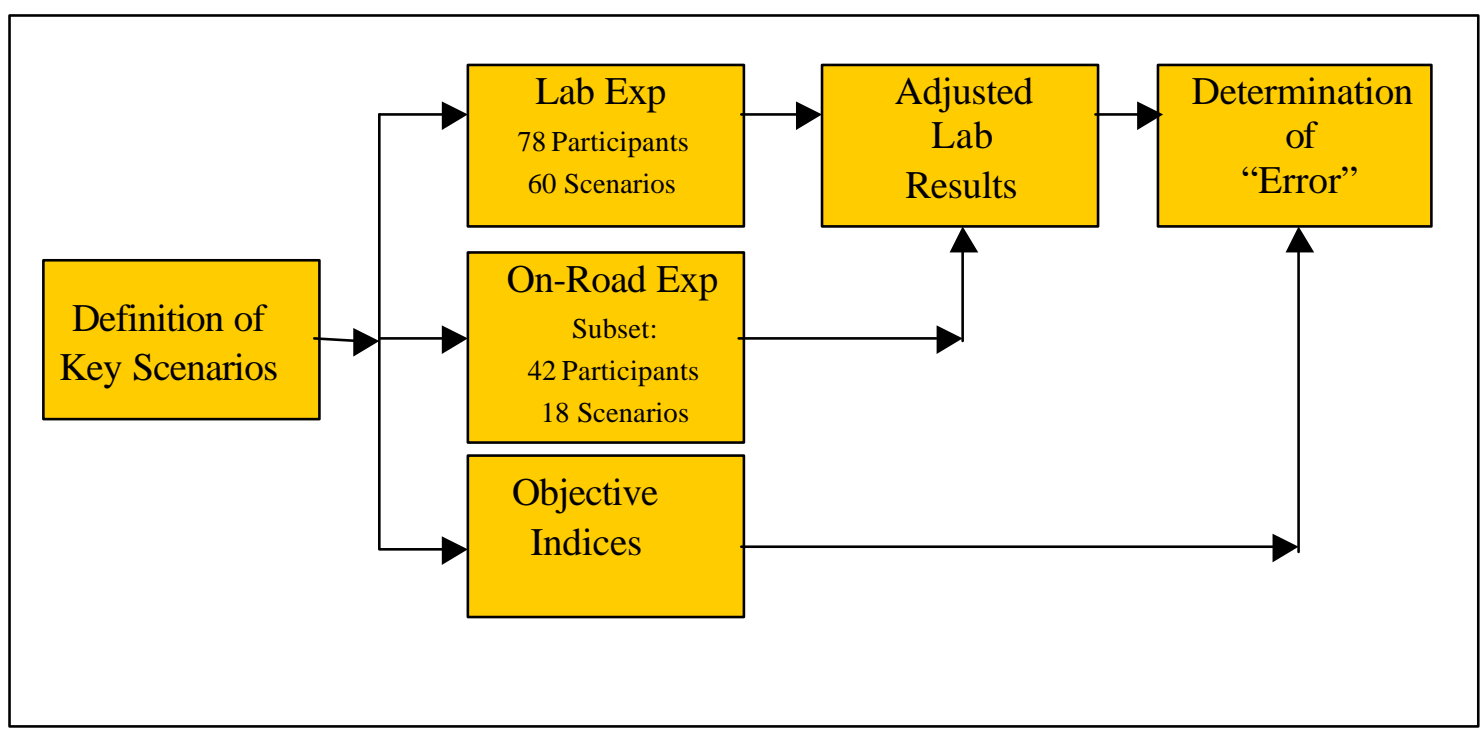

Figure 2-1. Sequence of activities.

Conceptually, what the experiment did was put a research participant in a particular driving scenario, obtain the participant's judgment about some aspect of time or space, obtain a parallel objective measure of the actual time or space required or available, and compare the perceived and objective measures to determine "error." However, there are three critical methodological concerns that had to be overcome and that helped determine the structure of the experiment: (1) 
people are quite poor at expressing perceptions in terms of formal measurement dimensions (e.g., seconds); (2) while driver perceptions would be ideally studied under controlled conditions, laboratory display media may result in optical distortions; and (3) while on-the-road judgments can be used (thus overcoming the previously mentioned problem), such methods are inefficient, difficult to control, costly, and for certain scenarios, hazardous.

To deal with these concerns, a combination of laboratory video and on-road methods was used, whereby the on-road data were used to calibrate relative measures obtained in the laboratory. A wide range of situations was presented to research participants as videotaped stimuli in a laboratory portion of the experiment. For a subset of these laboratory situations, using a subset of the participants, the same judgments were made for the nominally identical situation on the road, using an instrumented vehicle. This approach resulted in a set of calibration benchmarks to adjust laboratory findings to provide a more realistic estimate of on-road perception.

To overcome the problems of having people try to translate their perceptual judgments into time or distance units, participants simply pushed a hand-held button at the time or location he or she judged an event would have occurred. For example, if the participant were viewing a vehicle approaching on a crossroad from the right, the view of that vehicle would be occluded at some specified point prior to reaching the participant's location (e.g., $4 \mathrm{~s}$ away). The participant's task was to press the button at the moment he or she believed the approaching vehicle would be directly in front of the participant vehicle. This same technique was applied for both the laboratory and on-road measures, at the same intersection.

Figure 2-1 presents an overview of the research activities. After the details of all scenarios were defined, laboratory and field trials were conducted. Data on the key timing and spatial elements of driving maneuvers were collected for all participants in the laboratory and should be viewed as the primary data from this study. In this approach, a subset of the participant sample participated in a small set of representative scenarios in the field to calibrate the subjective judgment data gathered in the laboratory. The adjusted lab data were then compared to objective measures of highway engineering models, expert judgments, and data that either alone or in combination approximate the same types of situations, behaviors and maneuvers experienced in the laboratory. The key factors effecting driver maneuver errors were then expressed as the difference between the objective and subjective measures collected.

The laboratory experiment included a total of sixty scenarios, where a scenario was defined in terms of the specific site and environmental conditions, the particular maneuver, and the specific perceptual judgment. Table 2-1 lists the sixty laboratory scenarios and indicates the subset of eighteen scenarios included in the on-road study. Ultimately, two of the laboratory scenarios (12 and 13) had to be dropped for methodological reasons, so that the final analysis included 58 scenarios.

Table 2-1 organizes the scenarios on the basis of the general type of perceptual judgment involved for the maneuver. The major groupings are: judgments about paths that are parallel to the plane of the participant's vehicle; judgments about paths that cross the subject vehicle; turning; signal phasing; stopping; and time to reach a location. 
Table 2-1. Scenarios selected for inclusion in lab and on-road studies.

\begin{tabular}{|c|c|c|c|c|c|}
\hline & \multirow{3}{*}{ SCENARIO } & & \multirow[b]{3}{*}{ On-Road } & \multirow{2}{*}{\multicolumn{2}{|c|}{$\begin{array}{l}\text { Subjective Judgements } \\
\text { Time/Space Adequacy }\end{array}$}} \\
\hline & & \multirow[b]{2}{*}{ Lab } & & & \\
\hline & & & & Available & Required \\
\hline & Allo_Path_fans & & & & \\
\hline 1 & Passina/2 Lane Hiahwav/Passenger CarLeadina & $\mathbf{x}$ & & & $x$ \\
\hline 2 & Passing/2 Lane Highway/Large Truck Leading & $\mathbf{X}$ & & & $\mathrm{x}$ \\
\hline 3 & Passina/2Lane Hiahwav/Large Truck Leadino/Wet & $\mathbf{x}$ & & & $\mathbf{x}$ \\
\hline 4 & Passina/2_Lane Highwav/No Leadina Vehicle & $\mathbf{x}$ & & $\mathrm{x}$ & \\
\hline 5 & Lane_Chanoina/Arterial/Beina Overtaken on Left & $\mathbf{x}$ & & $\mathrm{x}$ & \\
\hline 6 & Lane_Chanaina/Ereewav/Beina Overtaken on Left & $\mathbf{x}$ & $\mathrm{x}$ & $\mathbf{x}$ & \\
\hline 7 & Lane Chanqing/Freeway/Overtaking Vehicle on Right & $\mathbf{x}$ & & $\mathrm{x}$ & \\
\hline 8 & Lane Changina/Arterial/Moving to Left & $\mathrm{x}$ & & & $\mathrm{x}$ \\
\hline 9 & Lane Changina/Arterial/Movina to Right & $\mathbf{x}$ & & & $\mathbf{x}$ \\
\hline 10 & Lane Changina/Freewav/Moving to Left & $\mathbf{x}$ & $\mathbf{x}$ & & $\mathbf{x}$ \\
\hline 11 & Lane Changing/Freeway/Moving to Right & $\mathbf{X}$ & $\mathbf{X}$ & & $\mathbf{x}$ \\
\hline 12 & Lane Chanqing/Multiple Right to Exit Lane/LOS C-D & $\mathbf{x}$ & & & $\mathbf{x}$ \\
\hline 13 & Lane Chanaino/Multiple Riaht to Exit Lane/LOS E-F & $\mathbf{x}$ & & & $\mathbf{x}$ \\
\hline 14 & Meraina/Freewav/Hiah_Sneed & $\mathbf{x}$ & & $\mathbf{x}$ & \\
\hline 15 & Meraina/Urban/Low Speed from Parkina Snot & $\mathbf{x}$ & $\mathbf{x}$ & $\mathbf{x}$ & \\
\hline 16 & Merging/Freeway/High Speed & $\underline{\mathbf{X}}$ & & & $x$ \\
\hline 17 & Meraina/Urban/Low Speed from Parkina Snot & $\mathbf{x}$ & $\mathbf{x}$ & & $\mathbf{x}$ \\
\hline 18 & Oncomina Vehicle/Low Speed/Large Truck Anoroachina & $\mathbf{x}$ & & $\mathbf{x}$ & \\
\hline 19 & Oncomina Vehicle/Low Sneed/Passenger Car Anoroachina & $\mathbf{x}$ & $x$ & $\mathrm{x}$ & \\
\hline 20 & Oncomina Vehicle/Low Sneed/Motorcvcle Anoroachina & $\mathbf{x}$ & & $\mathbf{x}$ & \\
\hline 21 & Oncoming Vehicle/High Speed/Large Truck Approaching & $\mathbf{x}$ & & $x$ & \\
\hline 22 & Oncomina Vehicle/Hiah Speed/Passenger Car Approaching & $\mathbf{x}$ & $\mathbf{x}$ & $\mathrm{x}$ & \\
\hline 23 & Oncomina Vehicle/Hiah Speed/Motorcvcle Approaching & $\mathrm{x}$ & & $x$ & \\
\hline & secingath_eans & & & & \\
\hline 24 & Gap Judging/Arterial/2 Lane From Right & $\mathbf{X}$ & & $x$ & \\
\hline 25 & Gap Judging/Arterial/2 Lane From Left & $\mathbf{x}$ & & $x$ & \\
\hline 26 & Gap Judaina/Arterial/Divided_From Riaht & $\mathbf{x}$ & & $\mathbf{x}$ & \\
\hline 27 & Gan Judaina/Rural Hiahwav/From Riaht & $x$ & $x$ & $\mathrm{x}$ & \\
\hline 28 & Gap Judaina/RuraL_Hiahwav/Erom_Left & $\mathbf{x}$ & $x$ & $x$ & \\
\hline & Gap Judging/Divided Rural Highway/From Right & $\mathbf{X}$ & & $\mathrm{x}$ & \\
\hline & ming & & & & \\
\hline 30 & Turning Left/Stopped at Divided Multilane Arterial & $\mathbf{X}$ & & & $\mathbf{x}$ \\
\hline 31 & Iurnina Left/Stopned at Undivided 2-Lane/Time to Clear & $\mathrm{x}$ & $\mathbf{x}$ & & $\mathrm{x}$ \\
\hline 32 & TurninaLeft/Stonned at Undivided 2-Lane/Achieve Sneed & $\mathbf{x}$ & $\mathbf{x}$ & & $x$ \\
\hline 33 & Turning Riaht/Stonned at Undivided 2-Lane/Achieve Sneed & $\mathrm{x}$ & $\mathbf{x}$ & & $x$ \\
\hline & Turning Right/From Driveway onto Arterial & $\mathbf{x}$ & & & $\mathbf{x}$ \\
\hline & matphasing & & & & \\
\hline 35 & Yellow Signal Phasing/Urban - $35 \mathrm{mi} / \mathrm{h}$ & $\underline{\mathbf{X}}$ & $\underline{\mathbf{x}}$ & $\mathrm{x}$ & \\
\hline & Yellow SianaL Phasina/Suburban $-50 \mathrm{mi} / \mathrm{h}$ & $\mathbf{x}$ & & $\mathrm{x}$ & \\
\hline & pping & & & & \\
\hline 37 & Emergencv Stop $/ 55 \mathrm{mi} / \mathrm{h} \&$ Level/Drv & $\mathbf{x}$ & $\mathbf{x}$ & & $\mathrm{x}$ \\
\hline 38 & Emergency Stop $/ 35 \mathrm{mi} / \mathrm{h} \&$ Level/Drv & $\mathbf{x}$ & $\mathbf{x}$ & & $\mathbf{x}$ \\
\hline 39 & Emergency Stop $/ 55 \mathrm{mi} / \mathrm{h}$ \& level $/$ Wet & $\mathbf{X}$ & & & $\mathrm{x}$ \\
\hline 40 & Emergency Stop $/ 35 \mathrm{mi} / \mathrm{h}$ \& Level $/$ Wet & $\mathbf{X}$ & & & $\mathrm{x}$ \\
\hline 41 & Emergency Stop $/ 35 \mathrm{mi} / \mathrm{h}$ \& Downarade/Drv & $\mathbf{x}$ & & & $\mathbf{x}$ \\
\hline 42 & Smooth safe_stoo $/ 55 \mathrm{mi} / \mathrm{h} \&$ Level/Dry & $\mathbf{x}$ & & & $\mathbf{x}$ \\
\hline 43 & Smooth safe ston $/ 35 \mathrm{mi} / \mathrm{h} \&$ Level $/ \mathrm{Drv}$ & $\mathbf{x}$ & & & $\mathbf{x}$ \\
\hline 44 & Smooth, safe stop $/ 55 \mathrm{mi} / \mathrm{h}$ \& Level $/$ Wet & $\mathbf{X}$ & & & $\mathrm{x}$ \\
\hline 45 & Smooth safe stoo $/ 35 \mathrm{mi} / \mathrm{h} \&$ Level $/$ Wet & $\mathbf{x}$ & & & $\mathbf{x}$ \\
\hline 46 & Headwav $/ 55 \mathrm{mi} / \mathrm{h} \&$ Level/Drv & $\mathbf{x}$ & $\mathbf{x}$ & & $\mathbf{x}$ \\
\hline 47 & Headwav $/ 35 \mathrm{mi} / \mathrm{h} \&$ Level $/ \mathrm{Drv}$ & $\mathbf{x}$ & & & $\mathbf{x}$ \\
\hline 48 & Headwav $/ 55 \mathrm{mi} / \mathrm{h} \&$ Level $/$ Wet & $\mathbf{x}$ & & & $\mathbf{x}$ \\
\hline 49 & Headway $/ 35 \mathrm{mi} / \mathrm{h}$ \& Level $/$ Wet & $\underline{\mathbf{X}}$ & & & $\mathbf{x}$ \\
\hline 50 & Headway/35 mi/h \& Downgrade/Dry & $\mathbf{X}$ & & & $\mathrm{x}$ \\
\hline 51 & Headway/55 mi/h \& Downgrade/Dry & $\mathbf{x}$ & & & $\mathbf{x}$ \\
\hline 52 & Headwav $/ 35 \mathrm{mi} / \mathrm{h} \&$ Downorade $/$ Wet & $x$ & & & $x$ \\
\hline 53 & Headwav $/ 55 \mathrm{mi} / \mathrm{h} \&$ Downorade/Wet & $x$ & & & $x$ \\
\hline 54 & Headwav/Freewav Merce & $\mathbf{x}$ & & & $\mathbf{x}$ \\
\hline & 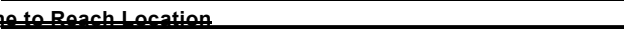 & & & & \\
\hline 55 & Reach Sianalized Intersection/Urban & $x$ & $x$ & & $x$ \\
\hline 56 & Reach Signalized Intersection/Rural & $\mathbf{X}$ & & & $\mathbf{x}$ \\
\hline 57 & Crossina from Stop/Arteria//Undivided & $x$ & & & $x$ \\
\hline 58 & Crossina from Ston/Arterial/Divided & $x$ & & & $\mathbf{x}$ \\
\hline 59 & Crossina from Ston/Rural/Hiahwav/Undivided & $\mathrm{x}$ & $x$ & & $\mathbf{x}$ \\
\hline & Crossing from Stop/Rural Highway/Divided & $\mathbf{X}$ & & & $\mathbf{X}$ \\
\hline
\end{tabular}


The data collection portion of the experiment involved two parallel data collection efforts, one in the laboratory using videotaped stimuli, and one on the road using an instrumented vehicle. A total of 77 participants took part in the laboratory experiment. A subset of 42 of these people also took part in the on-road experiment. Age groups were defined as follows: young drivers were 18 to 22 years old; middle-aged drivers were 30 to 45 years old; and older drivers were 70 years old or older.

Laboratory Experiment. Groups of research participants were tested simultaneously. The video display was projected on a screen using a projection television mounted on the ceiling. Participants sat in chairs with screening partitions separating them. The chairs were placed at a set viewing distance so objects on the screen subtended visual angles similar to those actually occurring on the road. Participants had two response devices at their stations. One was a simple button, used to make perceptual judgments. The other was a small rating console, used to make ratings of safety and attention.

The researcher provided an overview of the study, administered the instructions, and administered practice trials. Following this, data collection was begun. The set of scenarios associated with a given site began with the presentation of the overview montage that gave the viewer an orientation to the site. It showed the site and associated traffic from a variety of perspectives, while the voice-over message described the site in general terms. The idea was to give the viewer the same sort of general familiarity and expectancy that a driver might develop as he or she encounters an actual roadway site. The general instructions, reinforced several times during the course of the experiment, emphasized that "when we show you a stretch of roadway like the one you just saw, you must place yourself in the same situation and make your judgments as though it were you driving your vehicle."

Following this orientation montage, the scenarios were presented for perceptual judgments. Before each scenario, the video screen went blank, and specific verbal instructions about the perceptual judgment to be made were presented via digital audio files. Then the scenario itself was presented in the form of a brief clip. Clips generally began with a few seconds of orienting view, and a panning of the camera if it was relevant to the scenario. For example, if the scenario concerned the time required for a vehicle to cross an intersection from a point at a stop sign, the clip would begin with the camera view straight ahead. It would then pan left and right for a view in either direction, just as a driver would look, before returning to the forward view. After a brief period, the video screen would go blank, indicating the initiation of the maneuver. The participant's task from that point was to imagine they were making the crossing maneuver. The research participant would press the button at the moment he or she felt that the rear of the vehicle would have cleared the intersection.

The specific procedures for judging the time or space available or required for a particular scenario were tailored to each scenario. In general, for the time available judgments, the research participant would be informed of the critical event to be judged, such as when the vehicle would arrive at an intersection ahead, or when a specific part of an approaching vehicle would be aligned with a point on the participant's vehicle. At a pre-determined point during the approach, the video screen would go blank. The participant then had to press the hand-held button at precisely the moment he or she believed the critical event occurred. In this manner, temporal judgments were obtained without requiring participants to work with units of time.

Similarly, for judgments of the time required for a maneuver, typically the screen would go blank to indicate the moment at which the participant's vehicle began the maneuver (e.g., crossing a 
roadway). The participant pushed the button to indicate the moment at which the maneuver was completed; instructions carefully detailed how this was to be defined in each case.

For those scenarios in which participants judged the distance required for a maneuver (e.g., emergency braking), the screen did not go blank. Rather, an acoustic signal indicated when the maneuver began, and the participant's task was to press the button when the vehicle got to the point on the roadway at which the maneuver would have been complete, i.e., the vehicle would have to come to a complete stop.

For those scenarios where the participant was required to judge the time or distance required for a particular maneuver, three ratings were made on a seven-point scale:

- $\quad$ Safety--Self: "Think about yourself as a driver performing a maneuver like this in a setting similar to this one. In general, how great a potential for safety problems do you feel there is when you are in this type of situation?"

- $\quad$ Safety--Others: "Think about the full range of other drivers on the road performing a maneuver like this in a setting similar to this one. In general, how great a potential for safety problems do you feel there is when other drivers are in this type of situation?"

- $\quad$ Attentional Demand: "How much attention would you have to pay to perform a maneuver like this in a setting similar to this one?"

The instructions explicitly defined what was meant by "safety problems," which included not only collisions directly involving the subject vehicle, but also that vehicle causing other drivers to take actions which could cause conflicts or disrupt traffic.

On-the-Road Experiment. The on-the-road experiment closely paralleled the laboratory experiment in terms of procedures and scenarios, so that direct comparisons could be made. Rather than viewing video images, the research participant viewed the situation from a vehicle on the actual roadway, with the experimenter driving the vehicle. The analog of the video screen going blank was the activation of vision-occluding goggles. The on-road experiment used a subset of the participants who also took part in the laboratory. The sequence in which the laboratory and on-road experiments were run was varied across participants.

The on-road experiment used a specially instrumented minivan, outfitted with a modified Data Acquisition System for Crash Avoidance Research (DASCAR) system. DASCAR is a research tool consisting of a variety of sensing and data acquisition equipment that records information on driver behavior and performance, vehicle performance, and roadway environment. The suite of equipment is illustrated in Figure 2-2.

Participants ran individually as passengers in the minivan. Data collection encompassed 18 of the 60 laboratory scenarios, as indicated in Table 2-1. On-road sessions were conducted only during clear weather and not during rush hour. 


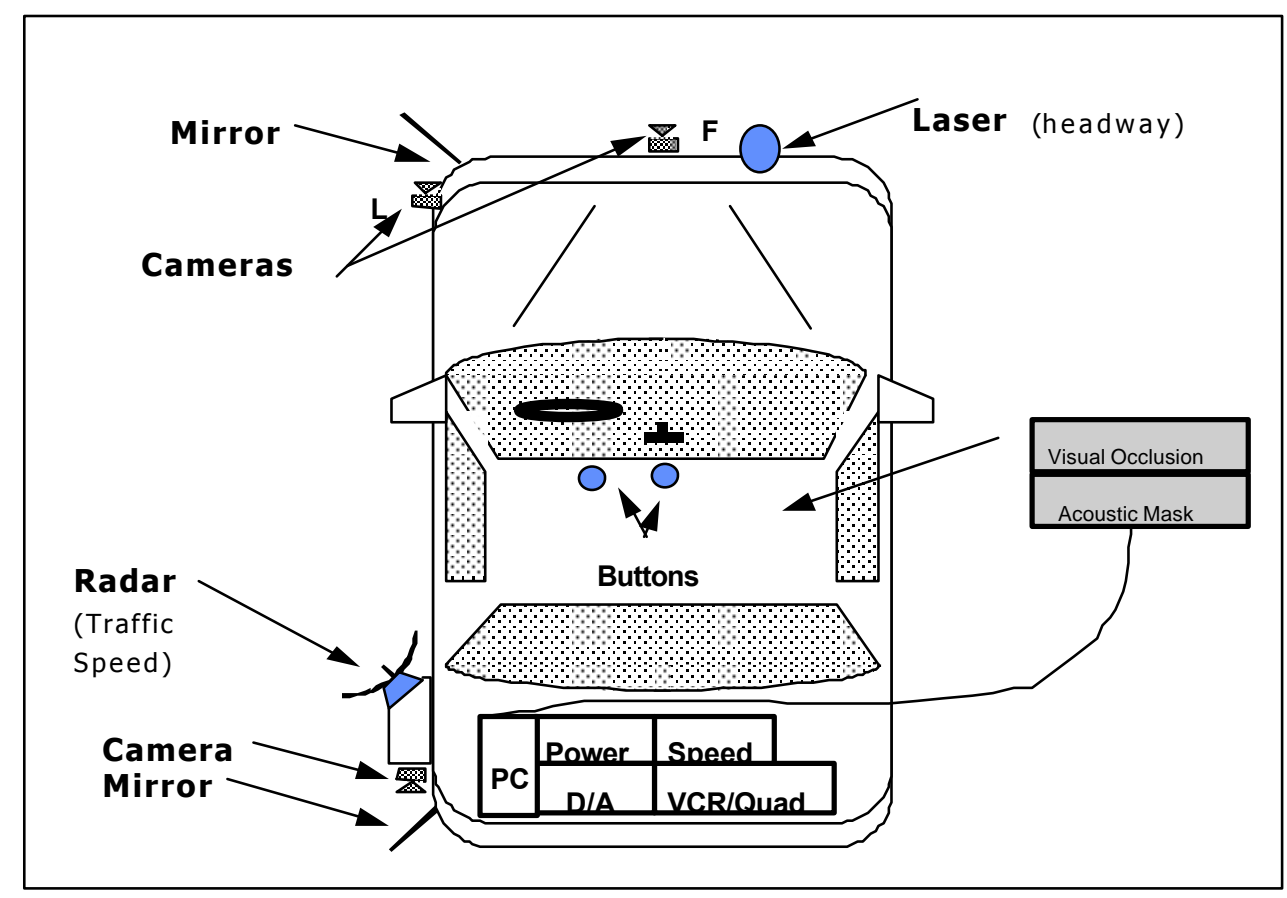

Figure 2-2. Instrumented vehicle components.

Determination Of Objective Time, Space, And Hazard. The actual time available to perform a maneuver was determined using the actual alignment between the test vehicle and a target vehicle or event. Measurements of the actual events were made according to the same definitions as used in instructions to participants. For example, in a scenario involving participant estimations of time available to turn right, participants were asked to press the response button when they thought the front of a vehicle coming from the right was directly in front of the center of their vehicle. The objective timing of this alignment was recorded on the auxiliary videotape recorded by the DASCAR's video recording system.

The development of actual driver time/distance requirements for designated hazard maneuvers involved application of theoretical and empirical human factors performance data, as derived from the literature and field observations. This process analyzed designated hazard maneuvers in terms of known components, e.g., hazard-recognition, response decision, brake-reaction, and vehicle response times. Literature input for the determination of maneuver requirements was largely derived from documented human factors field/laboratory studies and vehicle performance field tests. Where possible, actual performance times/distances were determined from data collected at field study sites. Applied procedures for field observations at study sites, controlled field observations, and relevant literature are briefly discussed.

Development of values to compare against participant ratings of safety problems was accomplished by a panel of highly experienced operational traffic engineers. The panel was comprised of three experienced engineers with extensive traffic engineering operational experience. These panel developed objective ratings for designated driver maneuver errors to serve as a basis for comparison with participant hazard estimates. 


\subsubsection{Key Research Findings and Implications}

This section highlights the key findings from an extensive analytic effort, the details of which may be found in Lerner, Steinberg, Huey, and Hanscom (1998). These major findings provided important input to the later Task D efforts on countermeasure development.

Before discussing the findings, some definition of the types of "error" measures used is required.

For many scenarios, it is not meaningful to directly compare participants' judgments of the time/distance available or required for the laboratory and on-road versions of a particular scenario. This is because the "actual" time/distance varied from trial to trial in the field. The experimenter could not control dynamic aspects of the roadway to the degree that the each onroad trial precisely matched the target speed and/or distance as it occurred in the laboratory version. For example, the on-road experimenter attempted to occlude the image of an approaching vehicle when it was some target value (e.g., $2.5 \mathrm{~s}$ ) away, but the actual time to arrival varied from person to person. Because of this variability, it is necessary to compare laboratory and on-road findings in terms of the magnitude of the error. The most appropriate manner of expressing the precision of the participants' perceptions is as a percent error, that is, the difference between perceived and target values, relative to the size of the target value. Expressing subjective estimates as a percent of the target ("correct") value not only accounts for variability among on-road trials for a given scenario, it also permits a meaningful comparison of perceptual error from one scenario to another.

In expressing the perceptual error, we have found it useful to describe the direction of the error relative to its safety consequences. A misperception in one direction will have the potential to directly contribute to a collision, whereas an error in the opposite direction will be safety conservative. For example, if a driver overestimates the time available for making a maneuver, he or she may accept a gap which actually does not provide sufficient time. If a driver underestimates the time available, he or she will only accept large gaps, providing an additional cushion in timing. In order to comprehend the implications of the data more easily, we have reported the findings in terms of "percent safety error." By this, we mean that the sign of the perceptual error is such that for any scenario, a positive safety error is an error in the safety conservative direction, while a negative safety error is an error in the more dangerous direction. Specifically, for the various scenario judgments made, percent safety error is defined as follows:

For Time Available:

$$
\text { Percent Safety Error }=\frac{\text { (Target Value - Participant Estimate) }}{\text { Target Value }} * 100
$$

For Time Required:

$$
\text { Percent Safety Error }=\frac{(\text { Participant Estimate }- \text { Target Value })}{\text { Target Value }} * 100
$$

For Distance Required:

Percent Safety Error $=\frac{(\text { Participant Estimate }- \text { Target Value })}{\text { Target Value }} * 100$

$$
\text { Target Value }
$$

Thus the magnitude of the error is expressed as a percentage, and the sign of the error is always with respect to its primary safety consequences. Negative safety errors are considered more serious than positive safety errors. 
The initial step in the analysis was to compare the laboratory and on-road data to determine what, if any, calibration factor might need to be applied to the laboratory findings.

The comparison of the laboratory and on-road data supported the following observations:

- There was a strong correlation between laboratory and on-road measures of the accuracy of judgments

- There was generally close agreement between the two data sets, with the exception of distance-based judgments (stopping distance, safe headway)

- There was no systematic bias to differences between the data sets for time-based judgments

- There was a bias for the distance based judgments, whereby laboratory judgments of required distance were greater than on-road judgments

- Various attempts at modeling the differences were not able to relate differences to any scenario factors, such as relative speed or angle of approach.

Based on these observations, the following conclusions regarding the use of the laboratory data for subsequent analysis are warranted:

- For time-based judgments, laboratory data may be used without any corrective transforms

- For distance-based judgments, the percent safety error obtained in the laboratory should be adjusted. Judgments of stopping distance should be adjusted by 82.5 percent of the original adjustment. Judgments of headway should be adjusted by 55 percent of the original distance judgment.

The reason for the discrepancy between the laboratory and on-road data for the distance-based judgments is not known. It could be related to the display medium, the importance of peripheral vision cues or non-visual cues on the road, or the difficulty of the task. In any case, the need for a substantial field correction factor suggests that the distance-based lab data may not be as reliable as the time-based data.

Summary data on perceptual errors is illustrated in Figure 2-1, Figure 2-2, Figure 2-3, Figure 2-4, and Figure 2-5. These present percent safety errors findings for time available scenarios, time required scenarios, distance required scenarios involving judgements of headway, distance required scenarios involving judgements of stopping distance, and combined scenarios, respectively. All of these figures use a similar "interquartile box plot" format. Each column represents a different scenario. The lower bound of each "box" shows the $25^{\text {th }}$ percentile and the upper bound shows the $75^{\text {th }}$ percentile. The median is indicated by the horizontal line within the box, and the mean is indicated by a cross. The range is shown by the vertical lines, with extreme outliers indicated by zeros. The horizontal band across each figure shows the zero value for percent safety error. Values above this line indicate a positive percent safety error (conservative), and values below indicate a negative percent safety error (danger). 


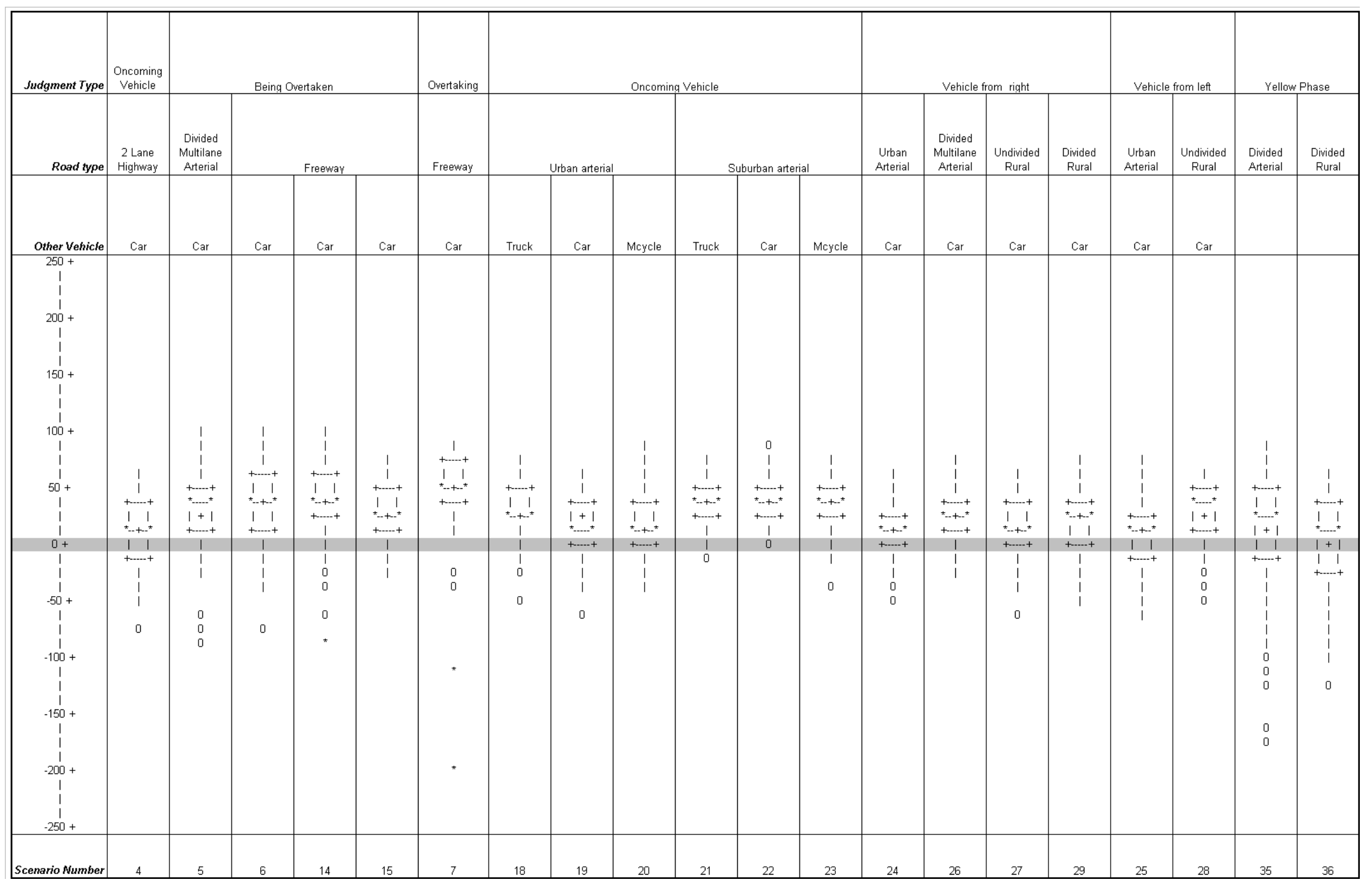

Figure 2-1. Time available scenarios, interquartile box plots of distribution of percent safety error. 


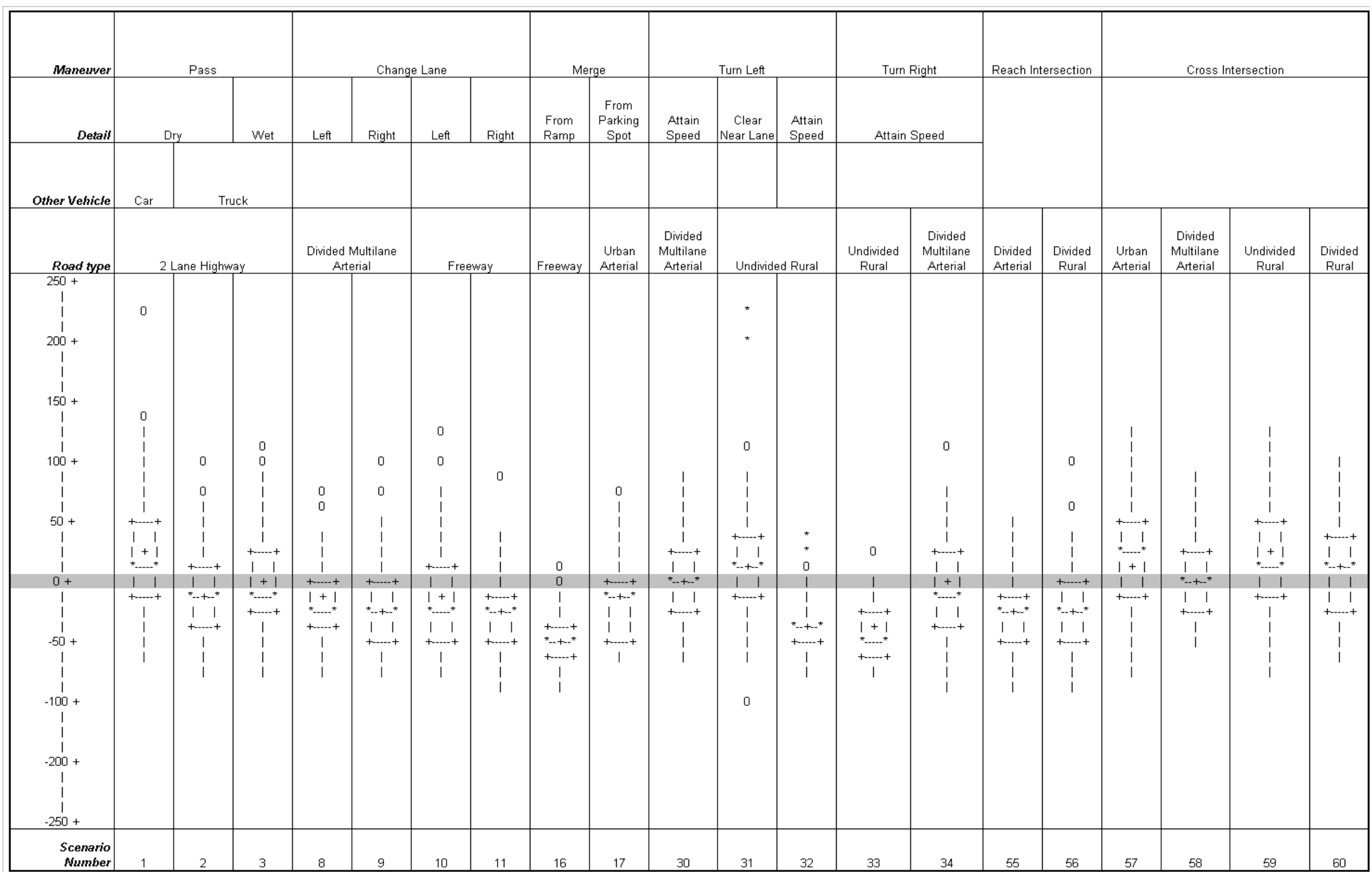

Figure 2-2. Time required scenarios, interquartile box plots of distribution of percent safety error. 


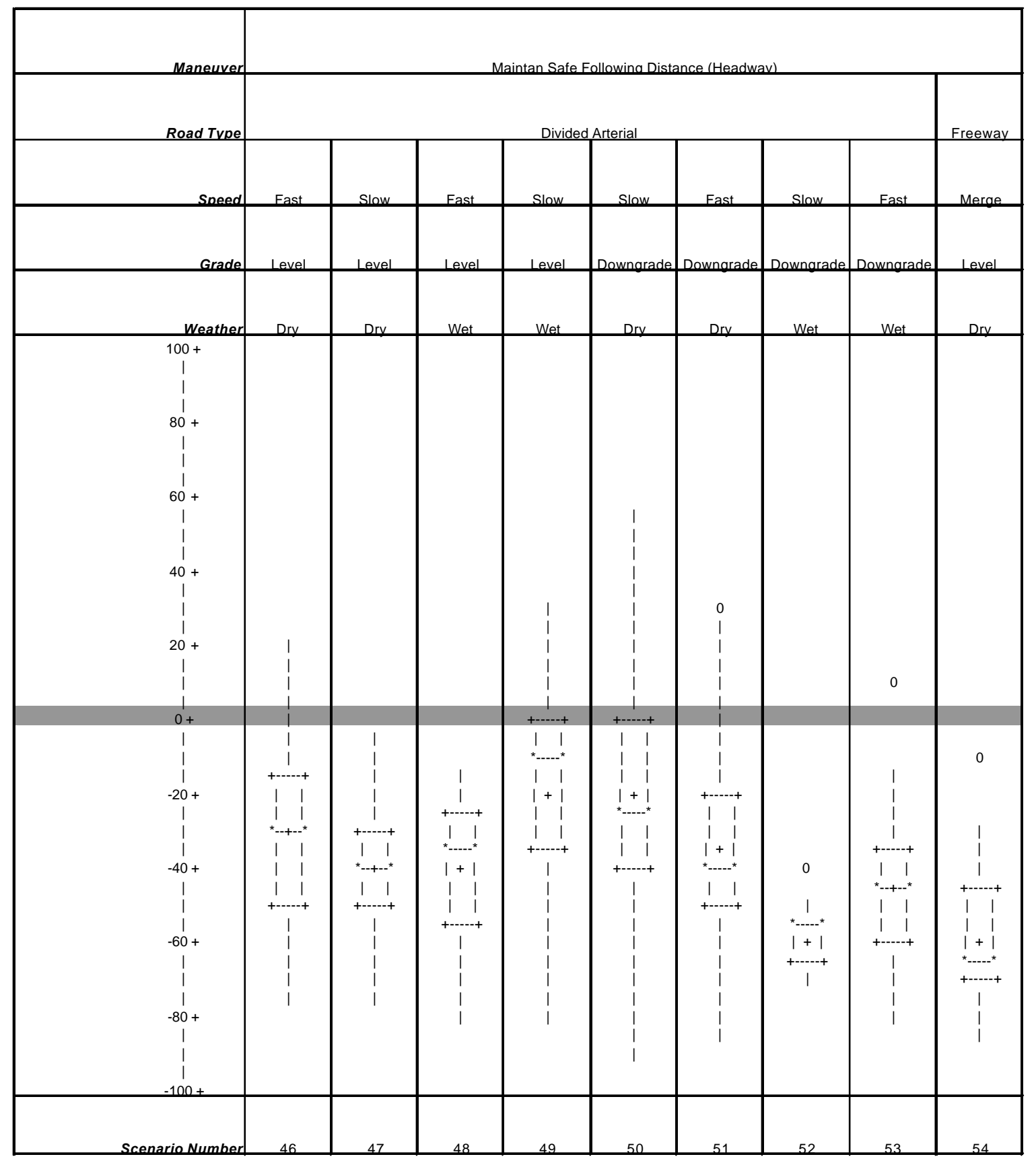

Figure 2-3. Headway distance required scenarios, interquartile box plots of distribution of percent safety error. ${ }^{1}$

\footnotetext{
${ }^{1}$ Headway judgments adjusted to 0.55 reported value.
} 


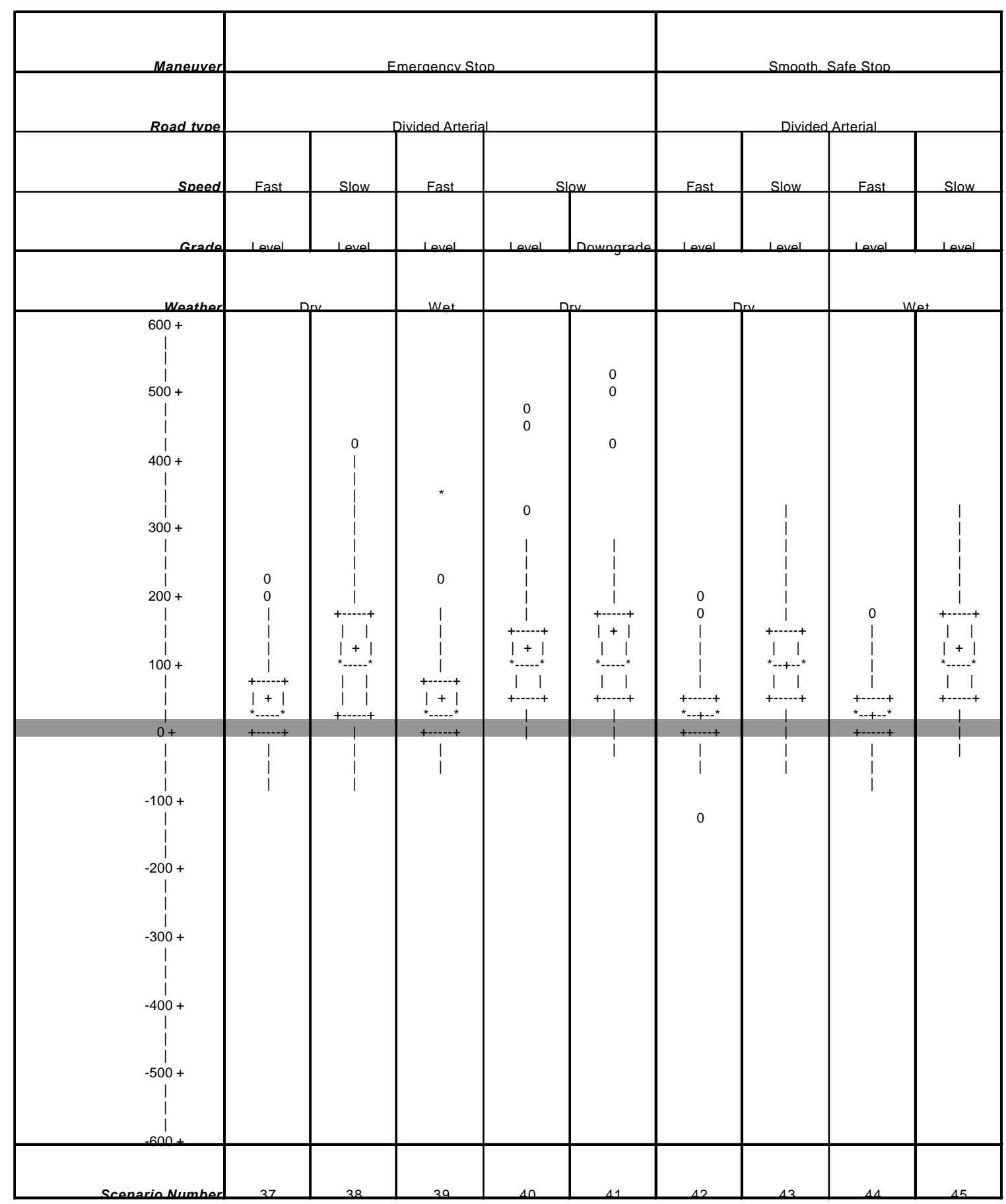

Figure 2-4. Stopping distance required scenarios, interquartile box plots of distribution of percent safety error. ${ }^{2}$

${ }^{2}$ Stopping distance adjusted to 0.825 reported value 


\begin{tabular}{|c|c|c|c|c|c|c|c|c|c|c|c|c|}
\hline \multirow{4}{*}{$\begin{array}{r}\text { Time } \\
\text { Required }\end{array}$} & Maneuver & \multicolumn{3}{|c|}{ Turn Left } & \multirow{2}{*}{\multicolumn{2}{|c|}{$\begin{array}{c}\text { Turn Right } \\
\text { Attain Speed }\end{array}$}} & \multicolumn{6}{|c|}{ Cross Intersection } \\
\hline & Detail & Speed & Lane & Attain Speed & & & & & & & & \\
\hline & Road Type & $\begin{array}{l}\text { Divided } \\
\text { Multilane } \\
\text { Arterial } \\
\end{array}$ & \multicolumn{2}{|c|}{ Undivided Rural Highway } & $\begin{array}{c}\text { Undivided } \\
\text { Rural }\end{array}$ & $\begin{array}{c}\text { Divided } \\
\text { Multilane } \\
\text { Arterial } \\
\end{array}$ & \multicolumn{2}{|c|}{ Urban Arterial } & $\begin{array}{c}\text { Divided } \\
\text { Multilane } \\
\text { Arterial } \\
\end{array}$ & \multicolumn{2}{|c|}{ Undivided Rural } & $\begin{array}{c}\text { Divided } \\
\text { Rural } \\
\end{array}$ \\
\hline & Other Vehicle & & & & & & & & & & & \\
\hline \multirow{3}{*}{$\begin{array}{r}\text { Time } \\
\text { Available }\end{array}$} & Judgment Type & $\begin{array}{c}\text { Vehicle from } \\
\text { Right }\end{array}$ & $\begin{array}{c}\text { Vehicle from } \\
\text { Left }\end{array}$ & $\begin{array}{c}\begin{array}{c}\text { Vehicle from } \\
\text { Right }\end{array} \\
\end{array}$ & \multicolumn{2}{|c|}{ Vehicle from Left } & $\begin{array}{c}\text { Vehicle from } \\
\text { Right }\end{array}$ & $\begin{array}{c}\text { Vehicle from } \\
\text { Left }\end{array}$ & $\begin{array}{c}\text { Vehicle from } \\
\text { Right }\end{array}$ & $\begin{array}{c}\text { Vehicle from } \\
\text { Right }\end{array}$ & $\begin{array}{c}\text { Vehicle from } \\
\text { Left }\end{array}$ & $\begin{array}{c}\text { Vehicle } \\
\text { from Right }\end{array}$ \\
\hline & Road Type & $\begin{array}{l}\text { Divided } \\
\text { Multilane } \\
\text { Arterial }\end{array}$ & \multicolumn{2}{|c|}{ Undivided Rural Highway } & $\begin{array}{c}\text { Undivided } \\
\text { Rural }\end{array}$ & $\begin{array}{c}\text { Urban } \\
\text { Arterial }\end{array}$ & \multicolumn{2}{|c|}{ Urban Arterial } & $\begin{array}{l}\text { Divided } \\
\text { Multilane } \\
\text { Arterial } \\
\end{array}$ & \multicolumn{2}{|c|}{ Undivided Rural } & $\begin{array}{c}\text { Divided } \\
\text { Rural }\end{array}$ \\
\hline & Other Vehicle & \multicolumn{3}{|c|}{ Car } & Car & Car & \multicolumn{6}{|c|}{ Car } \\
\hline & $\begin{array}{c}300+ \\
\mid \\
200+ \\
\mid \\
1 \\
1 \\
1 \\
\mid \\
1\end{array}$ & $\begin{array}{c}0 \\
1 \\
1 \\
+--++ \\
+--+-\end{array}$ & $\begin{array}{c}0 \\
1 \\
1 \\
+---+ \\
+--+-\cdot \\
+--.-+\end{array}$ & 1 & 1 & $\begin{array}{c}0 \\
1 \\
1 \\
+--+\end{array}$ & $\begin{array}{c}1 \\
1 \\
+--++ \\
*--+-\cdot\end{array}$ & 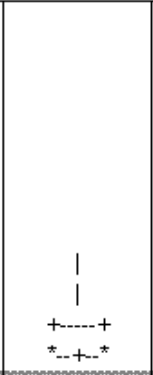 & $\begin{array}{c}0 \\
1 \\
1 \\
+--++ \\
*_{--+-+^{*}}\end{array}$ & $\begin{array}{c}0 \\
0 \\
1 \\
+--+ \\
+-+-{ }_{--+}^{*}\end{array}$ & $\begin{array}{c}0 \\
0 \\
1 \\
1 \\
+---+ \\
+--+- \\
+---+\end{array}$ & $\begin{array}{c}0 \\
0 \\
1 \\
+--++ \\
+-+_{--*}^{*}\end{array}$ \\
\hline & $\begin{array}{c}0+ \\
\mid \\
\mid \\
1 \\
-100+ \\
\mid \\
1 \\
1 \\
-200+ \\
\mid \\
1 \\
1 \\
-300+ \\
\end{array}$ & 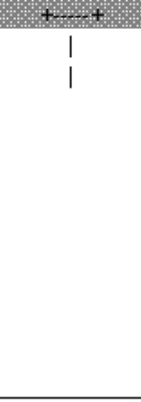 & $\begin{array}{l}1 \\
1 \\
0\end{array}$ & 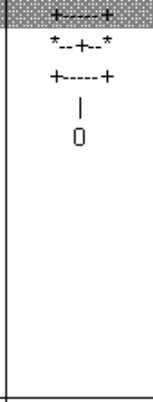 & 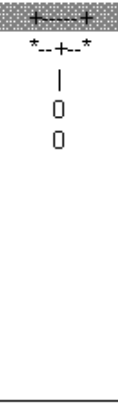 & $\begin{array}{c}1 \\
+\cdots+ \\
+\cdots\end{array}$ & 1 & $\frac{1}{+}$ & 1 & 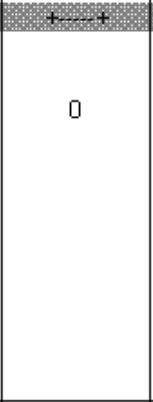 & $\begin{array}{l}1 \\
1 \\
0\end{array}$ & $\begin{array}{l}1 \\
1 \\
0\end{array}$ \\
\hline $\operatorname{Tin}$ & $\begin{array}{l}\text { Scenario Pair } \\
\text { Time Available) }\end{array}$ & 30,26 & 31,28 & 32,27 & 33,28 & 34,25 & 57,24 & 57,25 & 58,26 & 59,27 & 59,28 & 60,29 \\
\hline
\end{tabular}

Figure 2-5. Combined scenarios, interquartile box plots of distribution of net percent safety error. 


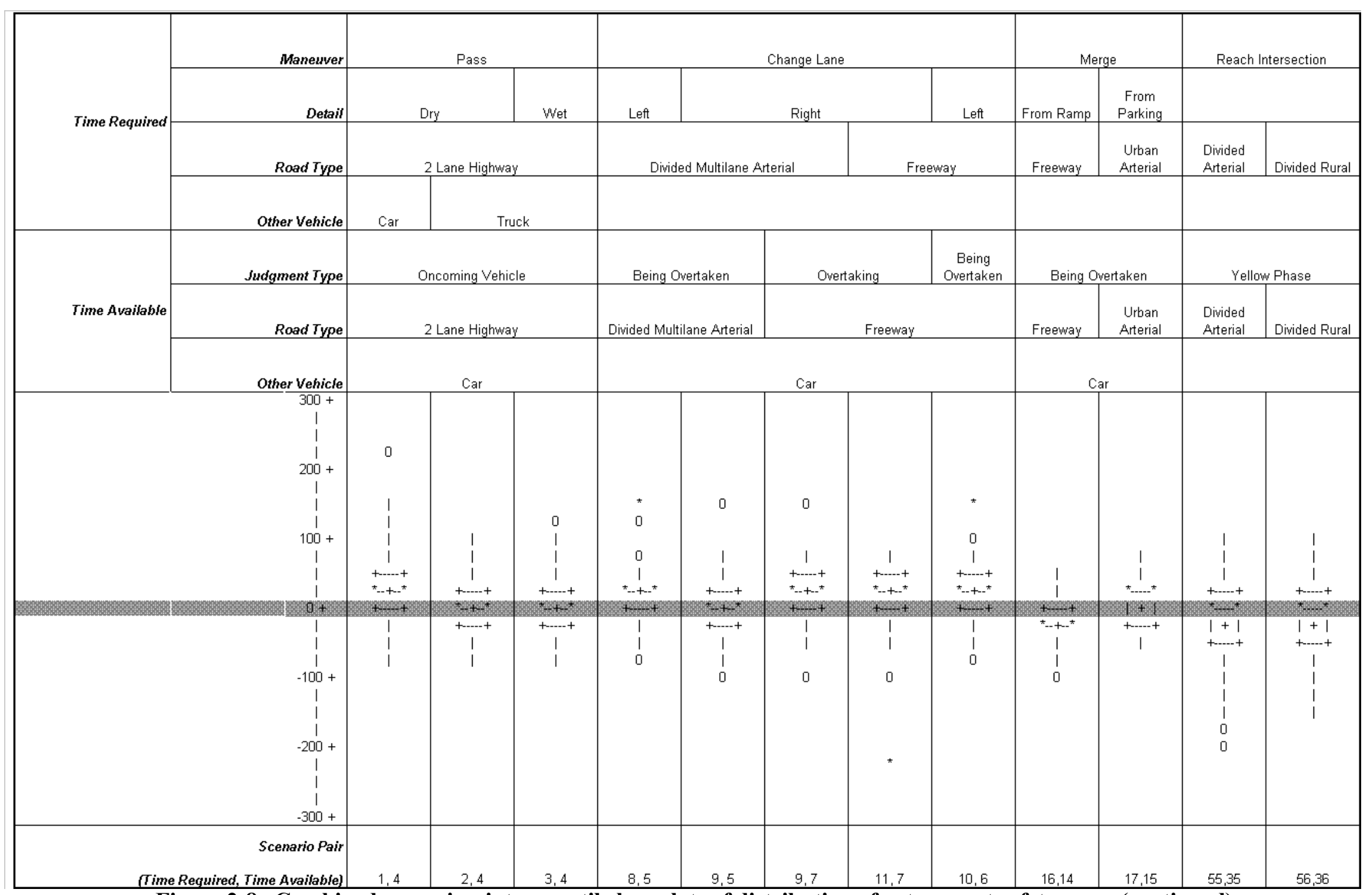

Figure 2-8. Combined scenarios-interquartile box plots of distribution of net percent safety error (continued). 
Based on the full analysis of the study, the following key misperceptions were highlighted:

Time Available to Make a Maneuver. Participants routinely under-estimated the time available before the arrival of a target vehicle. The error was typically on the order of 1 to $2 \mathrm{~s}$, and ranged from 10 to 47 percent of the actual value. Another way to express this is to say that the mean estimated time available for the various scenarios ranged from about 52 percent to about 90 percent of the actual times. This strong tendency to under-estimate the time available, as well as the magnitude of the observed errors, is typical of other experiments that have employed the timeto-contact method (see review by Hancock \& Manser, 1998). Because this error is in the safetyconservative direction, it would result in some safety margin for maneuvers, and so it is not a major safety concern here. However, there are a few exceptions, noted below. Another point to note is that while all age and gender groups showed positive mean safety errors for time available, this bias toward underestimation of available time was generally less pronounced for young (18 to 22 year old) drivers. The mean error for the middle-aged group was about halfagain longer than for the younger group. This means that younger drivers may have a smaller margin of safety, other things being equal. It also means that there may be conflicts or poor ability to predict the actions of drivers from different age groups. For example, a younger driver might assume that a driver ahead of him will accept a gap, and when this does not happen, there could be a front-to-rear collision.

An exception to the rule of generally safety-positive errors for time available was the case of judging the yellow phase of a traffic signal. For both suburban and rural signal locations, nearly a third of the participants over-estimated the time available until the red phase began. The variability among participants for these two scenarios was among the highest cases. The actual duration of the yellow phase was $4 \mathrm{~s}$ for the suburban arterial site (scenario 35) and $5 \mathrm{~s}$ for the rural highway site (scenario 36). Each scenario judgment was made $1 \mathrm{~s}$ into the interval, so the correct remaining yellow times were 3 and $4 \mathrm{~s}$, respectively. Given this, the magnitude of the errors was really quite large, especially for the rural site, where the $85^{\text {th }}$ percentile estimate was over $7 \mathrm{~s}$. Errors of these magnitudes could lead to improper decisions about whether adequate time remains to traverse the intersection. Misperception of the remaining yellow time was especially pronounced for older drivers, and this group is known to suffer an overrepresentation in collisions at signalized intersections (McKelvey \& Stamatiadis, 1987).

The final time-available case of particular concern was for the passing situation. About a third of the participants had safety-negative judgments regarding the moment at which the two vehicles (self and oncoming vehicle) would meet, with about 15 percent of participants erring by over $1 \mathrm{~s}$. This degree of error is much greater than for the other on-coming vehicle scenarios, in which the "self" vehicle is stationary. The difference might therefore be due to the speed of convergence (over $161 \mathrm{~km} / \mathrm{h}(100 \mathrm{mi} / \mathrm{h}$ ) for the passing case), the greater distance at the point of judgment, or perhaps the poorer resolution of the video image for this greater distance.

Time or Distance Required to Make a Maneuver. There was a much greater tendency for participants to misperceive in a safety-negative direction for judgments about the time or distance required for a maneuver, in contrast to the time available judgments. The problem was fairly general, such that across all 38 time or distance required scenarios, $61 \%$ of the judgments were safety negative, and in only 8 of these scenarios (all for stopping distance) was there fewer than 30 percent safety-negative judgments. Thus it appears to be a general result that people often err in that they do not fully appreciate the amount of time or distance required to safely complete a maneuver. However, there is also some ambiguity in these numbers, since the "actual" time required is based on traffic engineering practice and empirical distributions, and requires a variety 
of assumptions. It is therefore not clear to what degree the preponderance of negative safety errors represents misperceptions on the part of the participants, or more conservative criteria regarding a "safe" maneuver on the part of the highway safety experts. For some maneuvers, in particular headway maintenance, the frequency of safety-negative errors appeared to be very sensitive to the specific assumptions. When the "best estimate" target value assumptions were used, the vast majority of participants were deemed to accept unsafe headways. However, using the "minimum" reasonable parameters, only a minority of participants were deemed to accept unsafe headways. Thus, even within a reasonable range of assumptions, the headway problem can appear large or small. In most other cases, even using a less conservative definition of the "actual" time/distance required, a substantial number of safety-negative errors still remained. Thus it appears that people do not have a particularly accurate sense of how long it takes to complete a maneuver, or else they are willing to assume that quite aggressive driving actions are acceptable (e.g., high acceleration from a stop, rapid braking deceleration rates). There was some suggestion that males judged shorter stopping distances than females, but there was no suggestion of a comparable gender influence for maneuvers that involved acceleration rather than braking.

There appear to be particular problems in people's judgments of the amount of time required to achieve highway speeds when merging or turning onto a roadway. While some problems occurred even with lower speed roadways, when the maneuver involved a freeway merge or a left or right turn onto a rural highway, the average participant underestimated the time to achieve the speed of traffic by about $5 \mathrm{~s}$, and over 90 percent of judgments were safety-negative. Even using the more conservative "minimum" estimate of the actual time required, over 80 percent of the judgments were still safety negative. This type of error may lead to traffic conflicts, since vehicles approaching in the traffic stream might have to slow down to compensate as the subject vehicle is still accelerating up to the speed of traffic. Because of the magnitude of the apparent perceptual error, there was some concern that perhaps the "error" was actually due to overly conservative or otherwise inappropriate models of the maneuver used to generate the "actual" time required. In order to provide a reasonableness check, members of the project team executed similar maneuvers in their own vehicles and timed the points at which target speeds were reached. The predicted "actual" target values were very close to the observed times. Furthermore, the team members also suffered underestimates of the actual time that were very similar to those of the formal study participants. Thus it appears that there is a broad and substantial tendency for people to underestimate the time required to reach the speed of traffic, and this error is larger for higher speeds of traffic.

Another maneuver that appears noteworthy is that of approaching an intersection. Participants routinely underestimated the moment at which they would reach an intersection, typically on the order of about $1 \mathrm{~s}$, although about 15 percent of participants had double this negative safety error. Over 80 percent of all the estimates were safety-negative. This underestimate is potentially dangerous at signalized intersections because a driver may misjudge his or her ability to clear the intersection before the red phase. If the actual time to reach the intersection is longer, this could result in conflicts with cross traffic or in dangerously abrupt stopping. The underestimate may also be a concern at uncontrolled intersections or pedestrian crossings, if the driver assumes he or she will clear a conflict point prior to the time that another vehicle, pedestrian, bicyclist, or other conflicting road user reaches that point.

There also seems to be some tendency for people to underestimate the stopping distance (emergency stop, smooth safe stop) required at higher speeds. Although the majority of participants erred in the safety-positive reaction, there were two-to-three times more negative safety estimates for the $55-\mathrm{mi} / \mathrm{h}(88.55-\mathrm{km} / \mathrm{h})$ scenarios than for the $35-\mathrm{mi} / \mathrm{h}(56.35-\mathrm{km} / \mathrm{h})$ scenarios, for both wet and dry pavement conditions. For the higher speed stopping distance 
scenarios, from 20 to $35 \%$ of participants had safety-negative judgments. Often, these errors were sizable. The $15^{\text {th }}$ percentile participant under-estimated the emergency stopping distance by about $10 \%$, and the smooth safe stopping distance by considerably more. Thus participants, while certainly recognizing that stops at higher speed required more distance, were not sufficiently sensitive to the amount of additional distance required. While actual underestimates were not typical of the majority, they were frequent enough to be of concern for such a fundamental factor. This has implications for many situations involving speed selection.

Finally, when the "target" value for following headway was used to evaluate errors, it appeared that participants were quite prone to underestimate safe following headway. However, this proved to be quite sensitive to the assumptions made in determining the "actual" safe headway, so the findings are difficult to interpret. They do at least suggest, however, that the assumptions made by participants are less conservative when vehicle following than those assumptions made by traffic engineers.

Total Error for Scenarios. When the errors in judging maneuver requirements are considered jointly with the corresponding errors in judgment of time available, a few of these net error situations stand out as being of particular concern.

The worst cases for the combined error generally were the same scenarios as were discussed above for the time or distance required judgments. That is, only those scenarios with the most serious over-estimates of time or space available emerged as particularly bad when the time available and the time required estimates were combined. The primary exception to this was for the situations that involved passing a truck on a rural highway.

The three cases that involved entering the traffic stream and reaching the prevailing traffic speed for higher speed sites were the worst cases in terms of both the magnitude and the frequency of negative safety errors. These were the left and right turns onto a rural roadway and a freeway merge from an entrance ramp. The net safety error was about $-4 \mathrm{~s}$ for these situations, with over 90 percent of individuals having safety-negative net scores. No other scenario pairs approached these levels. Although the error is substantial, the actual point of conflict is not at the intersection or merge point itself, but somewhere downstream, where the faster moving approaching vehicle would overtake the merging vehicle. This provides some time and space for the approaching vehicle to adjust its speed to avoid a collision. While this might result in operational conflicts, it certainly reduces the risk associated with the substantial misperception. One might even speculate that the adjustments in speed made by approaching drivers helps train people in the misperception of the actual temporal gaps.

The situations with the next more substantial net paired safety errors were those involving the approach to a signalized intersection. The net error, due to perception of the time required to reach the intersection and the time remaining in the yellow signal phase, was negative for 59 percent of individuals. Older participants had particular problems for this pair. Similar rates of negative net safety values occurred for the situations that involved passing trucks.

Across all 23 scenario pairs, about 40 percent of individual scores were safety negative. For 17 of the pairs, more than one-fourth of the individual cases were negative. Thus there is a rather general concern with potentially dangerous misperceptions. This parallels the general tendency of participants to underestimate the time required to execute a maneuver. 


\subsection{Recommended Targets for Countermeasure Development}

The research findings suggest a number of areas in which drivers tend to misperceive the situation in a way that could contribute to a collision or traffic conflict. Several situations may be suggested as the most prominent targets for development of safety countermeasures. These include the following:

- $\quad$ Approach to Signalized Intersections. Several serious misperceptions relate to negotiating a signalized intersection. More than 30 percent of participants over-estimated the amount of yellow phase time that was available. More than 80 percent underestimated the time it would take them to reach an intersection. When these two errors are considered together, 59 percent of all participants had a combined error in the safety-negative direction. That is, it would appear to them that they could more easily clear the intersection in the remaining signal phase time than is actually the case. The problem was evident for both the urban and higher-speed rural intersections. Compounding this problem, substantial numbers of participants under-estimated the distance required to make a smooth, safe stop; for the higher speed road, over half of these judgments were safety-negative. Taken together, these findings suggest that there are frequent serious misperceptions related to decisions about approach speed and go/no go decisions at signalized intersections, especially those at higher speed. In addition to those drivers whose misperceptions might lead them to make misjudgments in the signal dilemma zone, the degree of variability among participants in general suggests other sorts of problems. Participants were highly variable in judging the amount of yellow-phase time they thought was available, with estimates of less than $1 \mathrm{~s}$ to those exceeding 8 or 9 s. Differences in judged safe, smooth stopping distances spanned several hundred feet at

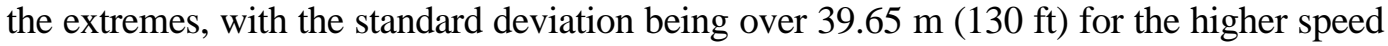
road. The frequent substantial perceptual errors in both directions suggest that there will be many traffic conflicts and misjudgments about another driver's likely actions. The findings suggest that misperceptions related to signalized intersections may be especially problematic for older drivers.

- $\quad$ Left or Right Turns from Stop on Higher-Speed Roadways. Participants generally under-estimated the time they had available before a conflicting vehicle from the left or the right reached them. This tendency existed for both urban and rural locations, and the typical magnitude of the misjudgment was on the order of about $1 \mathrm{~s}$ (or 10 to 28 percent). In contrast, participants frequently underestimated the time it would take to accelerate and achieve traffic speed during left or right turns, and this underestimate was both more frequent and more extreme for the turn onto the higher speed rural highway. The large majority of participants had safety-negative judgments of the time to achieve speed at the rural site (96 percent for left turn, 97 percent for right turn), with a group mean underestimate that approached $5 \mathrm{~s}$ ( $4.7 \mathrm{~s}$ for left turn, $4.8 \mathrm{~s}$ for right turn, or about a 40 percent error). As a result, when the two judgments were considered jointly, the large majority of participants ( $>90$ percent) had net safety-negative combined estimates. This type of error would result in potential conflicts with approaching vehicles, causing them to slow down in order to avoid a rear end collision. In addition to the threat of collision with the subject vehicle, this could also result in conflicts with vehicles following the initial approaching vehicle.

- $\quad$ Freeway Merges. Participants' perceptions of the gap available while being overtaken by a faster vehicle on the freeway were not particularly worrisome. Relatively few 
people overestimated the actual time available. However, two other types of errors cause the freeway merge situation to be of concern. First, participants grossly underestimated the time required to achieve traffic speed from the initial $48.3 \mathrm{~km} / \mathrm{h}(30 \mathrm{mi} / \mathrm{h}) \mathrm{ramp}$ speed. The group mean estimated time to merge and reach speed was $5.6 \mathrm{~s}$, whereas the target estimate of actual time was $11.4 \mathrm{~s}$ ("minimum" estimate was $7.3 \mathrm{~s}$ ). Thus, the average error exceeded $5 \mathrm{~s}$, and virtually all participants (97 percent) had negative safety errors. Even though the perception of the available gap was reasonably accurate, when the judgments of time available and time required are combined, there is still a very sizable net error, and 97 percent of all participants had safety-negative combined judgments. Compounding this problem, participants also permitted unacceptably short following headways while traveling on the ramp. With a target headway value of $32.6 \mathrm{~m}$

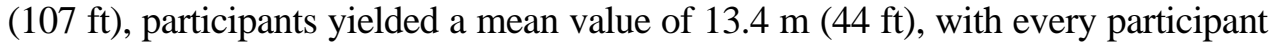
having a safety-negative judgment. Even using the "minimum" estimate of actual

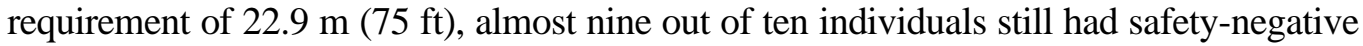
judgments. The combination of errors in time to reach speed and in following headway suggest that misperceptions will cause conflicts, with both ramp traffic and mainline traffic, during merging maneuvers.

- $\quad$ Passing. About one-third of the participants over-estimated the time that was actually available during a passing maneuver (two vehicles approaching one another), although this error exceeded $1 \mathrm{~s}$ for only 15 percent of subjects. This error, however, was compounded by frequent under-estimates of the time required to pass a vehicle, especially when that vehicle was a truck. Participants recognized that it took more time to pass a large truck than a car, but underestimated the degree of this additional time, with the majority of participants having safety-negative errors for the truck conditions. When time-available and time-required judgments were taken together, substantial numbers of participants had safety-negative combined estimates for passing a truck (56 to 58 percent); fewer were safety-negative for passing a car (26 percent). The problem was more pronounced for younger participants. Other judgments also related to safety for passing situations. People routinely under-estimated how long it would take them to overtake a slower-moving vehicle in the lane to their right (freeway scenario); about 94 percent of judgments were under-estimates. The mean estimated time was only about half of the actual time it took (1.6 vs. $3.1 \mathrm{~s}$ ). Likewise, participants routinely underestimated how long it actually takes to make a freeway lane change (about 73 percent safety-negative judgments for a lane change to the left, and about 88 percent safetynegative for a lane change to the right). Since a passing maneuver is composed of a lane change to the left, an overtake, and a lane change to the right, the errors in each of these component elements suggests a potential for serious errors during passing maneuvers.

- Merging from Parking Lane into Traffic Lane. Participants tended to under-estimate the amount of time available to them before a vehicle approaching from behind reached them in a parked car on an urban arterial. This would result in their being more reluctant to pull out in front of an approaching vehicle. However, they also under-estimated the amount of time it would take them to pull out and achieve the speed of traffic, which would increase the likelihood of pulling out in front of the vehicle. As a result, a substantial portion (44 percent) of participants had a net safety-negative value when the two judgments were considered together. That is, the error in judging maneuver time was more sizable than offsetting misconception of the time available for at least a sizable majority of participants. This type of error would cause the approaching driver to have to slow down to avoid a rear end collision. While this typically may not be safety critical, it could cause traffic conflicts and operational problems. 
- $\quad$ Speed Selection. Driver speed selection was not directly studied in this experiment, but it is presumably related at least in part to the driver's perceived ability to stop the vehicle. The findings of the experiment suggest that at higher speeds $(88.55 \mathrm{~km} / \mathrm{h}(55 \mathrm{mi} / \mathrm{h}))$, a sizable proportion of individuals underestimated the actual distance they would require in order to stop (emergency stop or smooth stop) their vehicle. This was by no means universally true; the majority of participants actually over-estimated the required stopping distance. However, 20 to 35 percent of individuals had safety-negative judgments for the higher-speed situations. While other situations may have yielded more frequent or extreme errors, this error in stopping estimates is of concern, given how many types of driving situations it may relate to. Presumably, underestimating stopping requirements will lead to inappropriate speed selection for higher speed roads, thus contributing to a wide range of collision types.

- $\quad$ Headway Maintenance. Headway selection appears to be a problem, but the data are more questionable. Whether a given following distance is deemed too close depends quite critically on the assumptions made about brake response time, deceleration rates, pavement friction, and so forth. Using a best-guess "target value," the vast majority of participants (84 to 100 percent at higher speeds, 66 to 100 percent at slower speeds) accepted inappropriately short headways. However, using less conservative, but still reasonable assumptions, there were relatively few inappropriate headways (12 to 28 percent at higher speeds, 8 to 23 percent at slower speeds). Taken together with the findings regarding misjudgments of emergency stopping distance, the results suggest that there is probably a misperception, or at least lack of appropriate conservatism, in people's selection of following headways. The problem is more pronounced at higher speed.

- $\quad$ Maneuver Time in General. While specific situations have been highlighted here, it should also be kept in mind that there was a broad tendency for many drivers to underestimate the time required to execute maneuvers in general. Across the full set of 20 time required scenarios, almost two-thirds of all judgments were safety negative, and for every scenario, at least 30 percent of individual values were safety-negative for scenarios. Thus the problem, and related countermeasures, might also be viewed from this more general perspective.

\subsection{Development of Countermeasures: Expert Panel}

Task D of this project was the point at which the findings of the various analytic and empirical efforts of preceding tasks were brought together to identify promising safety countermeasure approaches. This section describes how an expert panel was used to help develop the countermeasure concepts.

\subsection{Method}

The development of countermeasure concepts was centered around the use of an expert panel to help critically interpret research findings and their implications. Preliminary countermeasure concepts were developed by the project team as parts of the Task A and Task $\mathrm{C}$ activities. The role of the expert panel was to consider the findings of the research experiment, the initial countermeasure concepts, and their own expert knowledge of the broader research literature, engineering practice, regulations, and legal considerations. Based on this, a set of most- 
promising concepts was to be developed for recommendation for subsequent research and evaluation.

The panel consisted of seven highly-regarded experts in highway safety and driver behavior, with expertise in traffic engineering, human factors, enforcement, driver perception and behavior, expert testimony, problems of older and younger drivers, and intelligent transportation systems. For the panel workshop, these experts were joined by three members of the project team, as well as a representative of the FHWA office sponsoring the research. A list of expert panel attendees is provided in Appendix A.

Prior to the expert panel meeting, each participant was sent a packet of materials. These included an explanation of the objectives of the meeting, an overview of the project research methods, detailed findings of the Task $\mathrm{C}$ research, and preliminary countermeasure ideas raised in earlier tasks. The participants studied these materials prior to the meeting and also considered additional countermeasure concepts that might be considered at the meeting. In order to help systematically consider the range of approaches, the panelists were asked to think about how a given problem might be approached through any of seven general strategies:

$\begin{array}{ll}\text { - } & \text { Highway design } \\ \text { - } & \text { Traffic operations } \\ \text { - } & \text { In-vehicle systems } \\ \text { - } & \text { Active traffic control devices } \\ \text { - } & \text { Enforcement strategies } \\ & \text { Other (e.g., environmental modifications, driver education, vehicle design) }\end{array}$

The preliminary countermeasure concepts illustrated various examples of these categories of countermeasure approaches.

The panel convened for a full-day meeting, with follow-up activities. The session began with a review and critical examination of the Task $\mathrm{C}$ experimental methods and findings. Following this, the panel developed a set of key issues around which to focus countermeasure concepts. These issues were then discussed individually, considering the Task $\mathrm{C}$ research findings, what else is known from the literature, current practice, and recent activity (e.g., new research or practice, standards activity, new technologies). For each issue, a set of countermeasure recommendations was developed, along with commentary on various concerns related to the concept. As an aid to comprehensive consideration of alternative approaches, the set of general countermeasure strategies provided in the pre-meeting mailout was refined, as shown in Table 3-1.

The goal at this point was not to develop group consensus on the ultimate benefit of some concept, but rather to identify a range of potentially promising ideas that might prove beneficial to highway safety. The group was clear that countermeasure "recommendations" were suggestions for concepts to be evaluated through subsequent research and development. The panel was not attempting to put forward any consensus recommendations about whether some countermeasure concept should be adopted. 
Table 3-1. General categories of countermeasures for consideration

\begin{tabular}{ll}
\hline \multicolumn{1}{c}{ Type of Countermeasure } & \multicolumn{1}{c}{ Examples } \\
\hline $\begin{array}{l}\text { Highway Design } \\
\text { Roadway Features } \\
\text { Design Details }\end{array}$ & $\begin{array}{l}\text { Roundabout, rumble strip } \\
\text { Length of acceleration lane, shoulder width }\end{array}$ \\
\hline Traffic Operations & Signal timing, ramp metering, speed limits \\
\hline Traffic Control Device - Passive & Signs, markings, delineators \\
\hline Traffic Control Device - Active & Speed feedback \\
\hline System Level Changes & Uniform signal timing \\
\hline ITS, Decision Aids & Gap sensing/measuring at intersection \\
\hline Vehicle-Based Displays & Collision avoidance warnings \\
\multicolumn{1}{c}{ In-vehicle Information } & Rear signaling systems \\
\hline Enfernal Displays & Photoenforcement \\
\hline Perceptual Illusion & Of own speed, other's speed, surface quality \\
\hline Other & Public information campaign, legislation \\
\hline
\end{tabular}

Following the panel meeting, the countermeasure concepts identified and the related discussion points were summarized by the project staff and circulated to the panel members. The panel members reviewed this summary for accuracy and completeness. They also rated the various concepts in terms of their priority for further research and evaluation. The ratings were made on a five-point scale, where " 1 " was the least promising ("bad idea with minimal promise or bad side effects") and "5" was the most promising ("extremely promising idea that should definitely be implemented or seriously tested"). Finally, this post-meeting summary document gave the panelists an opportunity to add comments of any sort regarding a concept (design ideas, caveats, etc.).

The panel members returned the annotated summary documents to the project team, which then revised the summary to reflect comments and corrections. Panelist ratings of priority were also summarized.

\subsection{Panel Recommendations}

The panel recommendations are summarized here in a hierarchical manner. At the highest level, the panel discussion is organized by the driver maneuver errors that the countermeasures address (e.g., car following, turning into traffic). Under each maneuver heading, the various countermeasures discussed by the panel are listed. For each countermeasure, specific features of the countermeasure are described, if there was such discussion. Finally, additional points raised by the panels are given. These might include caveats, opinions, related needs (e.g., public education), and so forth.

The panel discussion touched on some approaches that were more general than the specific maneuver error problems dealt with in the research (e.g., safety audits). Discussion also arose for some maneuvers that, while specific, were not dealt with in the previous tasks (e.g., freeway exit ramps). Notes regarding these aspects of the panel discussion are also included below. The panel also noted that there were some specific situations (e.g., skew intersections) that were not addressed in the experimental work, which tended to focus on more prototypical cases. The key issues raised in this regard are also listed below. 


\section{Cross-Cutting Countermeasures:}

- Promote design consistency, sustainable safety concept.

- Uniformity will promote more accurate driver expectancies and judgments.

- Conduct safety audits.

\section{Car Following Countermeasures:}

- Install roadway gap zone markings.

- Install periodic road markings to define minimum safe headway, based on design speed or traffic speed.

- Post related signing to indicate location and meaning of markings.

- Effectiveness of roadway gap zone markings depends on traffic conditions: Do not expect to be effective at higher traffic densities; people are aware of shortness but select gap to keep other traffic from cutting in.

- Do not necessarily expect drivers to comply with full 2 s gap, but still might shift headway distribution, increase risk awareness.

- Freeway ramps might be a useful application, but one problem is that ramp speed is not constant, so estimated target following distance is not determinable; however, might still be useful as a reminder.

- Public education about the meaning of any new markings is absolutely essential.

- Install roadway monitoring sensors.

- Install sensors to provide driver feedback regarding following distance.

- Post a roadside display of message (e.g., "following too closely") or headway time (e.g., $1.0 \mathrm{~s})$.

- Can use existing hardware (loop detectors) or ITS equipment.

- Must clearly be independent of enforcement applications.

- Do not expect to be effective at higher traffic densities; people are aware of shortness but select gap to keep other traffic from cutting in.

- Implement selective photoenforcement.

- Panelists viewed selective photoenforcement as having potential value only if selectively applied, for example, for extreme violations, aggressive driving, or problem sites; not for broad approach to violations.

- The panel was uncertain as to whether there is anything in code objectively defining an unsafe headway; is there a basis for issuing a violation?

\section{Left or Right Turns Into Traffic Countermeasures:}

- Install an intelligent alerting device at intersections to alert drivers of potentially conflicting vehicles.

- The panel expressed a general concern with intelligent devices taking decisions out of drivers' hands; there could be consequences for vigilance and attention.

- Collision Countermeasure System (CCS) is an example of an intelligent alerting device under evaluation. A CCS system would alert primary road vehicle to presence of vehicle 
at crossroad and alert a vehicle stopped at crossroad of approaching main road traffic. It would provide an indication, via icon, that there is a vehicle to left or right. It may also provide a go/no go recommendation to the driver who is stopped at the crossroad.

- Panelists expressed concern as to whether installation of a system such as the CCS would result in non-compliance with stop signs.

- Panelists articulated the problem that a CCS system cannot "know" what maneuver the stopped vehicle is planning; therefore the system's recommendation would have to be based on most conservative case.

- Liability concerns exist regarding taking the decision-making role from the driver.

- Present information to the stopped vehicle on the time-to-arrival of approaching vehicle(s).

- Reporting time (seconds) itself may not be meaningful to many drivers without training or experience.

- Install standard distance cues.

- Signs, markings, colored pavements, etc., of standard size may be placed at a standard distance from intersection.

- Standard distance cues could aid driver judgment of speed and distance.

- Such markings may also serve to alert a driver on the main road of an intersection ahead.

- Equip vehicles with daytime running lights.

- Canadian data suggest effectiveness in reducing collisions; not clear if it is due to improved detection and/or enhanced perceptual judgment.

- Evaluate, and where necessary, upgrade intersection lighting to improve accuracy of distance/time estimation at night.

- Improved intersection lighting may benefit drivers on both major and minor approaches.

- Provide an active warning at intersection when a speeding vehicle is approaching at higher than normal speed.

- Vehicles travelling at unusually high speeds are the vehicles most likely to be misjudged by a driver turning into its path.

- Practice speed enforcement, including photoenforcement, to reduce outlier speeds.

- This application should target the extreme speeder, not more typical speeding.

- Reiterate good practice, e.g., sight distance.

- Design intersection to ease the turning maneuver while keeping speed up.

- Left turn tracking path through complex intersections with multiple turning lanes.

- Larger radius curves, where greater speed is desirable (e.g., not urban setting where traffic calming is desirable, not where high pedestrian usage).

- For wide and unbalanced intersections, extend centerline delineation farther toward point of intersection, so left turning driver has a better sense of where entrance to his section of the roadway is, moves around conflicting side.

- Move nose of raised median back from intersection, use painted median at that point, to allow left turning drivers a more efficient path. 
- Selective application of these ideas should be implemented only where appropriate, not universally recommended; warrants must be defined.

- Consider roundabouts as an alternative to intersection.

- Concerns remain with roundabouts regarding pedestrian and bicyclist safety and other driver performance difficulties.

\section{Approach to Intersection Countermeasures:}

- Modify yellow phase to ease decision or reduce dilemma zone.

- No consensus was reached among panelists on the most promising strategy for modifying the yellow phase. Panelists presented suggestions to lengthen yellow (to match perceptions, provide more decision time), shorten yellow (easier perception, less error), leave practice as it is, and eliminate yellow phase altogether (simpler decision reduces ambiguity; would require associated increase in all-red interval to reduce conflicts).

- Increase all-red phase.

- Panelists expressed concern about the "respect" issue: drivers may learn the all-red phase has increased, and subsequently treat it as part of the yellow phase.

- Present a "countdown" type display in conjunction with the traffic signal.

- An example of a "countdown" display may be an hourglass icon.

- Message/display will require good R\&D and field evaluation.

- Present a strobe or flash yellow during last part of phase.

- Panelists expressed concern that this signal may be too short for drivers to react in time.

- Present a strobe to enhance message/warning if probable violation is projected.

- Present strobe based on vehicle trajectory.

- Improve traction at approach to the signalized intersection.

- Reduce braking distance and control through better pavement friction, through resurfacing, or draining (intersection pavement is frequently a site with poorly maintained surface).

- Re-evaluate the traffic signal design formula with respect to driver perception/ performance.

- Mark the dilemma zone.

- Mark the beginning of the zone or the entire zone.

- Optimize flow progression to reduce the need for the stop decision and braking maneuver, through intelligent signal timing.

- Implement red light photoenforcement.

- Photoenforcement would need to be selectively implemented, not over-applied; selection criteria must be determined. 
- $\quad$ Panelists expressed concern that accidents tend to be caused by vehicles entering well after the initiation of green for cross traffic; therefore, the main problem (at least for angle collisions) may not lie with decision-making in dilemma zone.

\section{Freeway Merge Countermeasures:}

- Lengthen merge lane.

- Revise design formula.

- Speed change lane length requirements are recommended by Michaels and Fazio (1989); see Transportation Research Record 1213.

- Lengthening must be of acceleration lane portion parallel to mainline, not the ramp.

- Convey concept of "merge," not "yield."

- Place more responsibility on mainline vehicle, who can control gap size in front of him; "merge" also has a more positive command connotation to the entering vehicle, might help reduce instances of sudden stopping when driver "chickens out" on ramp.

- A liability concern exists with taking responsibility away from the driver merging onto the main line. Therefore, while in principle this countermeasure may hold some promise, practical implementation may not be feasible.

- Separate rightmost through lane from other lanes, combining right lane and merge lane ("local lane" concept), before re-joining mainline lanes again.

- Examine merging into arterial traffic from off ramp.

- Install a queue detector on the off ramp to warn exiting vehicles.

- Problem of false starts and unexpected stops by lead vehicle while following driver is also looking back scanning for gaps.

- Meter flow.

- Indicate clearly where there is no merge area or acceleration lane; an effective TCD for this must be developed/evaluated.

- Lengthen taper, introduce acceleration lane between exit ramp and arterial

- Install intelligent signing regarding presence of available gaps.

- Install a "rabbit" cue to pace merging vehicles into gap.

\section{Passing Countermeasures:}

- Install ITS (forward sensing or GPS or vehicle-to-vehicle) warnings/decision aids.

- Even if reliable, question remains as to what the information is that should be presented to the driver (safety, time, distance, passing speed required); there may not be a good answer.

- Eliminate need for passing maneuver.

- Introduce passing zones where there is an extra lane.

- Develop three lane roads with alternating passing lane; three lane cross-section with a median that alternates sides.

- Re-examine current passing zones based on current prevailing speeds. 
- Many existing passing zones may be inadequate because original assumptions about vehicle speeds are no longer valid.

\section{Stopping Distance Countermeasures:}

- Promote driver experience/practice with braking at speed with a new vehicle (especially those vehicles equipped with $\mathrm{ABS}$ ).

- This may help, but will not replace, extended experience. Skill can decrease rapidly subsequent to training.

- Provide some means of conveying " $\mathrm{V}^{2}$ " information to the driver.

- Stopping distance, collision severity, “danger," etc., are related to the " $V$ " "rule.

- Develop and introduce an obstacle detection system that is sensitive to fixed objects.

\section{Maneuver Time (in General) Countermeasures:}

- Use ITS to open spacing when maneuvering requirements are sensed.

- Sense presence of areas where there are conflicts and interactions, such as weave sections.

- Sense actions of other traffic, e.g., recognize turn signals.

- Adapt vehicle spacing based on need, through something like intelligent cruise control.

\section{Key Issues Not Considered In Research Study}

- Countermeasures need to consider not only the prototypical situation but also the range of situations. During the panel meeting, several specific situations or maneuvers were mentioned that were not directly addressed in the project. These included:

- Skew intersections.

- Night driving, including aspects of visibility, headlamps, lighting, glare.

- Left turns at higher speed, wider divided roadways (decision on fly, angle approach).

- Merging from the left lane (may be different perceptual problem than from right).

- Left turn across oncoming traffic.

- Freeway exit ramps and merges onto arterials.

- Flying vs. standing pass. 


\subsection{Countermeasures Recommended for Future Research Studies}

One requirement of this project was to develop a set of countermeasure concepts recommended for future research in laboratory and field studies. These were cast in the form of research problem statements. Based on the analytic activities, the empirical research, and the expert panel discussion, a final set of seven research project statements was developed, some of which address more than one of the specific countermeasure concepts raised during the expert panel.

In selecting the topics for recommended research, a variety of factors were taken into consideration. These included:

- Potential benefit of the countermeasure treatment

- Practicality of the concept

- Lack of previous or current investigation of the countermeasure

- Attitude of the expert panel

- Ability to address comprehensively in a research study of reasonable scope

- Problem requires research, rather than policy making

- Exclusion of broad safety approaches, not very specific to our target problems (e.g., safety audits)

- Exclusion of intelligent transportation system (ITS) strategies based on widespread changes to the nation's vehicle fleet (e.g., vehicle-based warning systems); the focus was on roadwaybased treatments.

- Exclusion of driver training, public education, or general police enforcement approaches; again, the focus was on roadway-based treatments.

The format of the problem statements is modeled (with some expansion and modification) on that used by the Transportation Research Board for its Circulars. Each problem statement has a descriptive title, followed by a brief discussion of the problem it addresses. This is followed by a specific statement of the project objective, and a consideration of the proper scope of the work. Next comes a discussion of the sequence of tasks that should comprise the project. A set of descriptive keywords then follows. An estimate of project cost and time requirements follows. These should be taken as order-of-magnitude estimates only. Next we address considerations related to implementation of the countermeasure in actual practice. Finally, there is a summary of the potential benefits of the countermeasure.

A summary of the seven recommendations for research studies of countermeasure approaches is presented in Table 4-1. Following this summary table, the individual research problem statements are presented. 
Table 4-1. Summary of research problem statements.

\begin{tabular}{|c|c|c|}
\hline Title & Problem Area & Concept \\
\hline $\begin{array}{l}\text { Alternating Passing Lane } \\
\text { Geometrics and Traffic } \\
\text { Control Device Treatments }\end{array}$ & Passing & $\begin{array}{l}\text { Design, operational, and TCD } \\
\text { requirements to permit safe } \\
\text { implementation of three } \\
\text { lane roadways with } \\
\text { alternating passing lane }\end{array}$ \\
\hline Car Following Feedback & Headway Maintenance & $\begin{array}{l}\text { Passive and active treatments } \\
\text { that provide driver } \\
\text { feedback re adequacy of } \\
\text { vehicle headway }\end{array}$ \\
\hline $\begin{array}{l}\text { Traffic Signal Timing to } \\
\text { Account for Drivers' } \\
\text { Intersection } \\
\text { Misperceptions }\end{array}$ & $\begin{array}{l}\text { Approach to Signalized } \\
\text { Intersections }\end{array}$ & $\begin{array}{l}\text { Incorporate known driver } \\
\text { perception problems into } \\
\text { signal timing and clearance } \\
\text { interval criteria }\end{array}$ \\
\hline $\begin{array}{l}\text { Highway Geometrics and } \\
\text { Pavement Markings to Aid } \\
\text { Entering Traffic at } \\
\text { Intersections }\end{array}$ & $\begin{array}{l}\text { Approach to Signalized } \\
\text { Intersections and Turns } \\
\text { from Stop on Higher Speed } \\
\text { Roadway }\end{array}$ & $\begin{array}{l}\text { Markings and geometric } \\
\text { elements to reduce } \\
\text { intersection maneuver time } \\
\text { and path confusion }\end{array}$ \\
\hline $\begin{array}{l}\text { Standardized Intersection } \\
\text { Distance Cue }\end{array}$ & $\begin{array}{l}\text { Turns from Stop on Higher } \\
\text { Speed Roadways }\end{array}$ & $\begin{array}{l}\text { Standard TCD at standard } \\
\text { distance from intersections } \\
\text { to aid perception of } \\
\text { approaching traffic } \\
\end{array}$ \\
\hline $\begin{array}{l}\text { Conflicting Vehicle Warnings } \\
\text { at Non-Signalized } \\
\text { Intersections }\end{array}$ & $\begin{array}{l}\text { Turns from Stop on Higher } \\
\text { Speed Roadways }\end{array}$ & $\begin{array}{l}\text { Address key limitations of } \\
\text { current generation rural } \\
\text { intersection intelligent } \\
\text { warning systems }\end{array}$ \\
\hline $\begin{array}{l}\text { High-Speed Approaching } \\
\text { Vehicle Warnings at } \\
\text { Intersections }\end{array}$ & $\begin{array}{l}\text { Turns from Stop on Higher } \\
\text { Speed Roadways }\end{array}$ & $\begin{array}{l}\text { Active warning to stopped } \\
\text { driver when approaching } \\
\text { vehicle is at excessive } \\
\text { speed }\end{array}$ \\
\hline
\end{tabular}




\section{Alternating Passing Lane Geometrics and Traffic Control Device Treatments}

\section{Problem:}

Driving judgments regarding passing maneuvers are difficult. The laboratory research portion of this project (Lerner, Steinberg, Huey, \& Hanscom, 1998) found frequent, substantial errors with serious safety implications. The time available for a passing maneuver was overestimated about one-third of the time, with about 15 percent of all these judgments overestimating by more than a full second. Furthermore, the time required to execute a passing maneuver was frequently underestimated, especially when passing a large truck. No promising countermeasures have been identified to aid drivers in their passing-related perceptions or decisions. Consequently, the most promising way to address this problem is to reduce the need for passing maneuvers. Lack of passing opportunities also contributes to problems of close car following, which was also identified as a problem in the research study. One possibility is to use existing right-of-way to create three-lane highways. The center lane alternates the permitted direction of travel periodically, so that there are ample opportunities to pass slower vehicles in a parallel travel lane, rather than having to make a passing maneuver that requires moving into the oncoming traffic lane. In the past, there were concerns about the safety of such three-lane roads where the flow in the center lane reversed, because drivers might fail to recognize the changeover. However, there are now greatly improved low-cost TCD alternatives that might be used, for example, plastic barriers, flexible posts, rumble pavements, reflective sheeting, optically-limited signal displays, paints, raised pavement markers, active signing, etc. Also, implementation now can better account for driver expectancies and search behavior. Furthermore, research into highway geometric requirements has updated the state of knowledge applicable to passing requirements for a variety of vehicle types. It should therefore be possible to design a safe and effective method for implementing three-lane roadways with an alternating passing lane.

\section{Objective:}

The objective of the project is to develop geometric design requirements, operational guidelines, and traffic control devices to permit safe implementation of three lane roadways with an alternating passing lane. The project should evaluate the benefits of the most promising alternatives. The evaluation must take into account driver perception, comprehension, and passing decision-making related to the device treatments. The behavioral impact of various treatments must be evaluated in the context of known passing distance requirements in order to assess the feasibility of alternative passing lane concepts. The benefit/cost analysis will also consider relative construction costs of upgrading existing two-lane roadways to a three-lane operation versus current geometric policy, e.g., four-lane with median.

\section{Scope:}

The project should address improvements to current two-lane rural highways. The study should define the range of applicable geometric characteristics, in particular sight distance, horizontal and vertical curves, and passing opportunities. Both day and night driving must be considered. Performance of TCDs in inclement weather, including snow, must be considered in the evaluation of alternatives, even if not directly treated in experimental studies. 


\section{Anticipated Tasks/Methodology:}

1. Review research studies and engineering criteria for geometric design and implementation of passing zones, with particular attention to experience with three-lane facilities, and reversible or alternating lanes. Contact experts with past experience with related facilities to get information on operational experience, problems, successes, etc.

2. Conduct a detailed behavioral task analysis of driver use of three lane roadways and passing maneuvers, with particular attention to information needs, driver expectancy, and error potential.

3. Identify alternative traffic control devices for delineating and signing passing areas, taking into account past operational experience and driver information requirements. Identify existing TCD alternatives, and evaluate their applicability. Develop new TCD designs as required to address unmet needs.

4. Develop geometric design criteria for alternating passing lanes, with specific attention to transition section requirements. These criteria must provide for lane length, width, and buffer widths between opposing travel directions. Establish preliminary working guidelines, e.g., minimum overall travel distance recommendations, to determine when alternating passing lanes are feasible. Developed guidelines will specify (1) travel distance and transition section geometrics as a function of design speed, and (2) criteria for when directions may be reversed.

5. Conduct a laboratory evaluation of alternative means of delineating passing lanes and alternative strategies for operational aspects. Evaluation should include driver comprehension of TCDs, driver awareness of operational conditions, and appropriateness of driver decision making about passing.

6. Evaluate driver response to the most promising delineation treatments in a test track or closed course setting.

7. Conduct a controlled field study of the most promising treatment. The study should include appropriate control conditions and be of sufficient duration to identify transient novelty effects.

8. Conduct a benefit/cost evaluation of the proposed device treatment(s) and geometric alternatives.

9. Develop recommendations for three lane roadways with an alternating passing lane. Include warrants for use, operational and design guidelines, and TCD requirements.

10. Document the findings and recommendations in a final report.

\section{Keywords:}

Passing

Passing zone

Reversible lane

Three-lane roadway

\section{Cost/Time:}

$\$ 1 \mathrm{M}$ over 4.5 years. 


\section{Implementation:}

Findings should be disseminated to appropriate AASHTO and TRB committees and to state and local traffic agencies. New TCDs or non-traditional applications should be submitted to the National Committee on Uniform Traffic Control Devices for consideration as standards for this application.

\section{Potential Benefits:}

Implementation of three lane roads with alternating passing zones should yield safety benefits in terms of reduced collisions related to passing maneuvers (head on collisions, side swipes, run-offroad), which tend to be severe. There should also be reductions of rear end collisions related to close following. There may also be secondary benefits in terms of travel time. 


\section{Car Following Feedback}

\section{Problem:}

Drivers tend to accept following headways that are too short to allow safe stopping under emergency conditions. To some extent this may be intentional under congested conditions. However, it also appears that drivers overestimate their ability to control the situation. In the laboratory research portion of this project, Lerner, Steinberg, Huey, and Hanscom (1998) found that research participants were not very conservative in their assumptions about safe stopping distance. Although what constitutes a "safe" headway can be very sensitive to the assumptions one makes regarding response times and deceleration rates, following headways observed in the experiment, as well as those measured in actual traffic in other studies, are frequently shorter than what most highway safety specialists consider reasonably safe. Using "best guess" criteria, about 90 percent of all the research participants accepted minimum headways, across a range of scenarios, were shorter than the desired target values.

One reason for this problem may be that drivers experience little meaningful feedback about their choice of headway. Unless some severe event causes a sharp deceleration of the leading vehicle, there is no indication that they have been driving in error. Furthermore, because short headways are commonplace in traffic, there may be a sense that this must be safe and acceptable. One means of giving the driver feedback, and of dealing with undesirable norms, might be to provide some indication to the driver when a headway is unacceptably short. Vehicle-based headway warning systems are one means of addressing this issue, but there are also roadway-based strategies that do not depend on the widespread implementation of intelligent vehicle devices in the nation's vehicle fleet. Giving the driver feedback when the headway is too short may help influence the driver's decisions about appropriate headway.

\section{Objective:}

The project should develop and evaluate both low-cost passive treatments and active treatments that inform drivers if they are following too closely. Examples of passive treatments might include roadway delineation indicating the acceptable gap based on posted speed or colored or textured pavement sections. Drivers following too closely would not be able to see the entire delineated section. TCD concepts that provide specific messages or that indicate the level of hazard severity may be possible as well. Active treatments are based on sensing the actual separation between vehicles and posting a message or symbol to the driver if it is too short. The project should determine the effectiveness of alternative treatments in conveying the intended message, the effect this has on actual headway selection under a variety of operational conditions, the probable safety benefits, and the benefit/cost determination if the treatment is to be implemented.

\section{Scope:}

The project should consider a range of active and passive feedback techniques and a range of possible specific messages to be indicated (e.g., actual separation in time or space, warning message, level of hazard). The treatments should be evaluated for freeways and for arterial roads, under day and night conditions. The effectiveness of the method should be determined for a range of levels of congestion. The measures of effectiveness should include both immediate effects in the locale of the TCD and more general effects on driver headway choice. Because 
younger drivers are particularly likely to select short headways, the study should specifically include consideration of this driver group.

\section{Anticipated Tasks/Methodology:}

1. Problem definition: Review literature on any previous attempts to reduce following headways. Determine the perceptual and display requirements of TCDs for this application. Define the traffic engineering factors that must be taken into account for the design and implementation of such devices. Comprehensively review the highway safety research literature, roadway design formulas, and driver training/performance literature to define as rigorously as possible "safe" and "unsafe" car following criteria.

2. Design a set of alternative passive display devices and techniques for providing feedback on short headways. Include consideration of the specific display and message, as well as the devices and their placement.

3. Design a set of alternative active display devices. Consider what the message should be ("too close," actual time, etc). Consider how to display the message so that it is only available to the target vehicle (visual tuning).

4. Conduct driver focus groups to evaluate and refine the active and passive concepts. Select a set of most-promising alternatives to carry forward to experimental evaluation.

5. Evaluate alternative concepts in an experimental setting (laboratory, test track, and/or onroad). Measures of effectiveness should include detection and comprehension of the message, awareness of appropriate headways, choice of headway immediately following the message (local effect), and general effects on headway choice.

6. Field evaluate the most promising alternative(s). The evaluation should include both local and general effects on headway distribution.

7. Estimate the safety and operational benefits of implementing the TCD. Consider how extensive deployment would need to be, and how it would be implemented. Based on these considerations, conduct a benefit/cost analysis.

8. Develop guidelines, warrants for use, and formal design specifications.

9. Document the methods, findings, and recommendations in a final report.

\section{Keywords:}

Car following

Tailgating

Headway

Rear end collisions

\section{Cost/Time:}

$\$ 650 \mathrm{~K}$ over 4 years

\section{Implementation:}

The findings should be disseminated to state and local traffic agencies. Demonstration projects should be funded to encourage implementation and experimentation with the concepts. 


\section{Potential Benefits:}

The developed TCDs might have both local and general effects. To the extent there are local effects specific to the site where the device is implemented, the treatment will serve to lengthen headways at problem sites. Increased headways should reduce rear end collisions and lanechanging conflicts. Ideally there will also be more general benefits as drivers acquire a better sense of appropriate headway and as short headways become less acceptable to the driving public. While the effect on the headway distribution may not be dramatic, even a small but broadly general shift could provide significant benefits in collision reduction and traffic operational performance. 


\section{Traffic Signal Timing to Compensate for Drivers' Intersection Misperceptions.}

\section{Problem:}

Drivers tend to underestimate both the time it takes to reach an intersection and the amount of available yellow signal phase time. In the laboratory research portion of this project (Lerner, Steinberg, Huey, \& Hanscom, 1998), the problem was observed at both suburban and rural intersections; and the magnitude of judgment errors was often substantial. More than 30 percent of participants over-estimated the duration of the yellow phase; at the rural intersection site, this over-estimate exceeded 3 seconds for 15 percent of the participants. More than 80 percent underestimated the time it would take them to reach an intersection. Considering both of these judgments together, the net effect was an error in the safety-negative direction for well over half (59 percent) of the participants. Thus the combined effect of these two observed judgment errors is that driver may misjudge their ability to clear an intersection before the onset of the red signal phase. The obvious inherent danger is the increased risk of severe right-angle collisions.

Two different approaches have been considered in attempts to improve safety where drivers have difficulty with these judgments. One strategy is to make the yellow interval more informative by including additional information. For example, late in the yellow phase the signal might go to a flashing mode, or there might be a strobe effect. The other strategy is to modify the policies for signal timing, including the duration of the all-red clearance interval, in order to better relate to driver perception and behavior. The proposed project will comprehensively examine both strategies.

A review of the current ITE policy to determine traffic signal clearance timing revealed the lack of yellow phase sensitivity to intersection width, i.e., not allowing approaching drivers more time to clear wider cross-streets. While the all-red phase does consider intersection width, a problem remains in that many drivers currently expect the all-red interval and consider it as part of the clearance interval. Thus, the safety margin, as affected by driver misperception of yellow time, remains compromised.

\section{Objective:}

The objective of this project is to re-examine the fundamental approach to signal timing and information, based on current knowledge of driver perception and decision making problems. Project activity shall assess traffic signal clearance interval requirements and signal timing strategy with the objective of developing appropriate clearance-interval policies that consider the fact that drivers may underestimate both their distance from the intersection and yellow phase duration. All aspects of current ITE policy affecting yellow phase timing should be considered, including the current $1.0 \mathrm{~s}$ perception-recognition time.

Any revised policy must establish upper and lower clearance interval time limits with three objectives: (1) minimum time to allow for safe intersection clearance, (2) maximum time to discourage drivers from running the clearance interval, and (3) time variability limits to avoid driver expectancy violation.

Innovative methods of presenting signal clearance information to drivers shall also be considered. For example, Newton, Mussa, Sadalla, Burns, and Mathias (1997) evaluated a flashing amber in conjunction with a solid green indication to warn drivers of the impending onset of the solid amber indication. The proposed project should evaluate the benefits of the most promising 
alternatives. The evaluation must take into account driver perception, comprehension, and intersection-approach decision-making related to the tested alternatives.

\section{Scope:}

Developed signal clearance interval strategies/countermeasures must consider a range of applications to include a variety of intersection geometric conditions, e.g., crossing width, approach sight distance, operating speed, approach grade; and vehicle factors, e.g., type, length, and outlier speed characteristics.

The research and evaluation must also include consideration of specific driver age groups. Older drivers are important to consider explicitly, because they are over-represented in signalized intersection crashes, and because the Lerner et al. (1998) findings indicate they are particularly likely to overestimate the amount of remaining yellow phase time. Younger drivers are also important to consider, because this group is prone to decision errors at signalized intersections.

\section{Anticipated Tasks/Methodology:}

1. Review engineering criteria and research studies that pertain to establishing and implementing traffic signal clearance intervals, signal phasing, and displays. All parameters affecting yellow phase timing should be critically reviewed, including the current 1.0 second perception-recognition time. Contact experts/researchers with past experience to get information on concepts based on current research and operational experience.

2. Define study parameters: i.e., (1) roadway situations of interest, e.g., intersection width, type of traffic signal display, location on field of view, approach visibility time, approach operating speed, approach grade; and (2) perceptual and traffic engineering factors, e.g., driver yellow signal recognition times as affected by sight distance. Prioritize candidate study conditions for experimental applic ation.

3. Conduct a detailed behavioral task analysis of driver perception and response to negotiation of a signalized intersection (including yellow phase and clearance interval), with particular attention to information needs, driver expectancy, and error potential. Include consideration of how drivers make decisions under time stress and how attention is allocated on the approach to an intersection. Include specific consideration of the capabilities and behavior of older drivers and of young/inexperienced drivers.

4. Identify alternative methods for presenting traffic signal clearance interval to aid motorists with their understanding safe intersection approach requirements. Identify existing TCD alternatives, and evaluate their applicability. Develop new signal display techniques as required to address unmet needs.

5. Conduct a laboratory evaluation of alternative intersection crossing/turning TCD/icon aids and alternative strategies for operational aspects. Evaluation should include driver comprehension of TCDs, driver awareness of operational conditions, and appropriateness of driver decision making with regard to crossing/turning maneuvers.

6. Evaluate driver response to the promising candidate treatment set in a test track or closed course setting.

7. Select the most promising treatment(s) and conduct a benefit/cost evaluation. Determine a final set of specific treatments for field testing. 
8. Implement the most effective treatment in a field test that includes a range of signalized intersection types. Because the treatment may involve changes to familiar signal displays or practice, the field test must be coordinated with a local public education campaign and enforcement. Appropriate control locations must be included to account for the effects of these ancillary activities.

9. Develop recommendations for signal timing and clearance intervals and for signal information display. Include warrants for use, operational and intersection design conditions, and TCD requirements.

10. Document the findings and recommendations in a final report.

\section{Keywords:}

Signalized intersections

Yellow phase timing

Traffic signal timing

Clearance interval

\section{Cost/Time :}

$\$ 750 \mathrm{~K}$ over 3 years

\section{Implementation:}

The results are directly applicable to traffic control standards development and should be submitted to the National Committee on Uniform Traffic Control Devices for consideration. Findings should be disseminated to appropriate AASHTO and TRB committees and to state and local traffic agencies..

\section{Potential Benefits:}

This countermeasure system should reduce serious angle collisions at complex intersections. 


\section{Highway Geometrics and Pavement Markings to Aid Entering Traffic at Intersections}

\section{Problem:}

Intersections represent areas of high accident concentration and frequency. In many jurisdictions, the majority of all accidents are intersection occurrences. In the laboratory research portion of this project (Lerner, Steinberg, Huey, \& Hanscom, 1998), it was found that drivers entering intersections tended to underestimate the required time to complete their turning maneuvers and attain traffic speeds. Therefore, safety benefits may be derived from the modification of intersection geometric elements and pavement-marking components designed to enhance entry speeds of side road vehicles onto major roadways. Current applications of selected techniques (e.g., wide-radius turns, dashed turn-path tracking lines) are currently applied to accommodate safe and efficient intersection operations. However, more innovative applications of pavement markings combined with geometric features (e.g., painted extensions to receded median islands) may serve to enhance the perceptual effect of intersections and improve traffic operations without jeopardizing safety.

Potentially helpful highway geometric elements include wider curb-return radii, use of acceleration transition areas, and intersection islands, that ease turning movements for side street vehicles. Roadway markings that clearly define turning paths (particularly in the context of complex intersections with multiple turning lanes) offer the potential to simplify the driver's task, thereby affording various safety and operational benefits. More extensive and effective techniques are sought to creatively combine intersection geometric element and pavement marking systems to ease turning maneuvers and to assist motorists entering from side-roads to achieve speeds of mainline traffic.

\section{Objective:}

The project will develop innovative human-factors based applications of intersection pavement marking and geometric design component combinations. These traffic control systems shall be designed as to maximize their potential to improve traffic operations without jeopardizing safety. The systems should clarify the proper path and reduce the amount of driver attention required to track through the intersection, allowing more attention to be devoted to monitoring traffic, signals, pedestrians, and other aspects of the intersection. The intent is that the system will reduce the time required for a maneuver, reduce confusion and indecision about the appropriate path, and reduce the frequency of vehicle conflicts.

The project should evaluate the benefits of the most promising alternatives. The evaluation must take into account driver perception, comprehension, and intersection-crossing and/or turning decision-making related to the tested alternatives.

\section{Scope:}

This project concerns techniques for simplifying the driver's tracking through the intersection; it does not include issues related to traffic operations and right-of-way. Developed intersection design/marking systems must consider a range of applications to include a variety of intersection geometric conditions, e.g., lane number, channelization, highway classification; traffic conditions, e.g., service volume, truck mix; and other factors, e.g., signalization, maintenance requirements. Although the focus is on aiding the entering driver, the project must also consider impacts on pedestrians and pedestrian safety. 


\section{Anticipated Tasks/Methodology:}

1. Review engineering criteria and research studies that pertain to establishing and implementing intersection pavement markings and geometric design components. The review must also consider the functional impact of TCDs and geometric design elements as a system. Contact experts/researchers with past experience with related experience to get information on current research and intersection design and operational experience.

2. Define study parameters: (1) roadway situations of interest, e.g., geometric and traffic conditions, field of view, available response time; (2) perceptual and traffic engineering factors relevant to the tested intersection design/marking systems; and (3) visibility and expected performance ramifications of tested geometric design and pavement marking elements. Prioritize candidate study conditions for experimental application.

3. Conduct a detailed behavioral task analysis of driver use of identified intersection design/marking systems with particular attention to information needs, driver expectancy, and error potential. Also include analysis of any potential problems the system may cause for pedestrians.

4. Identify alternative innovative intersection design/marking systems to ease turning maneuvers and to assist motorists entering from side-roads to achieve speeds of mainline traffic.

5. Conduct a laboratory evaluation of alternative innovative intersection design/marking systems. Evaluation should include driver comprehension of intersection layout as communicated by the tested design/marking systems, driver awareness of operational conditions, and appropriateness of driver decision making with regard to crossing/turning maneuvers.

6. Evaluate driver response to the promising candidate treatment set in a test track or closed course setting. Conduct a controlled field study of selected promising treatments. The study should include appropriate control conditions and be of sufficient duration to identify transient novelty effects.

7. Conduct a benefit/cost evaluation of the proposed treatment(s).

8. Implement the most effective treatment in a field test that includes a range of different intersection characteristics.

9. Develop recommendations for intersection cross/turning aids. Include warrants for use, operational and design factors, and TCD requirements.

10. Document the findings and recommendations in a final report.

\section{Keywords:}

Intersection traffic control

Intersection design elements

Turning movement aids

\section{Cost/Time:}

$\$ 800 \mathrm{~K}$ over 4 years 


\section{Implementation:}

The results are directly applicable to traffic control standards development and should be submitted to the National Committee on Uniform Traffic Control Devices for consideration.

Findings should be disseminated to appropriate AASHTO and TRB committees and to state and local traffic agencies..

\section{Potential Benefits:}

This countermeasure system should reduce serious angle collisions at complex intersections. 


\section{Standardized Intersection Distance Cue}

\section{Problem :}

For a vehicle making a turning or crossing maneuver at an unsignalized intersection, judging the time to arrival of an approaching vehicle can be a problem. This is especially so for vehicles approaching at outlier speeds (substantially faster than typical traffic for the site). In the laboratory research portion of this project (Lerner, Steinberg, Huey, \& Hanscom, 1998), six scenarios were studied in which a vehicle was approaching from the left or the right; from 12 percent to 38 percent of the "time available" judgments over-estimated the actual time available. Combined with the consistent underestimation of time required for the maneuver that was observed, this indicates a need to help drivers make more accurate judgments. Although the experiment was not able to systematically vary a range of site features, the substantial differences in safety related error rates among the six scenarios indicates that some situations are more difficult to judge than others. If standard, perceptually effective cues were available to drivers at intersections, judgments of the time to arrival of approaching cross traffic might be more consistent and accurate.

For vehicles approaching an unsignalized intersection on the primary road, there is often a need to adjust speed to accommodate an entering vehicle, due to perceptual misjudgments or risky decisions on the part of the entering driver. The approaching driver must be alert to presence and location of the intersection and its potential for conflict. It is possible that a standard cue located at a standard distance from intersections will aid approaching mainline drivers in hazard awareness and appropriate decision making.

\section{Objective:}

The objective of this research project is to develop a standardized intersection distance cue and determine its usefulness in aiding entering/crossing drivers to judge available time and in aiding approaching drivers to be aware of potential conflicts. The project should determine under what conditions such cues should be used, what the traffic control devices should look like, and where they should be placed.

\section{Scope:}

The project should consider a range of passive TCD possibilities, such as signs, markers, pavement markings, or pavement surface color/treatment. The evaluation should include both rural roadways and arterial roads, with a range of approach speeds, and day and night conditions. Approach road geometry, including horizontal and vertical curves, and number and width of lanes, should be considered.

The full range of driver age should be incorporated into the study, since the young driver group in Lerner et al. (1998) showed a smaller margin of safety for this situation, and since older drivers may have more perceptual difficulties with proposed TCDs.

\section{Anticipated Tasks/Methodology:}

1. Problem definition: Define the roadway situations of interest, based on accident and operational experience. Determine the site factors that are relevant to the study. Define 
the human perceptual and traffic engineering factors relevant to potential TCDs for this application.

2. Develop alternative TCD concepts/designs for the selected situations.

3. Conduct experimental research (laboratory, test track, simulator, and/or roadway) to evaluate various TCD design and placement strategies. Because the idea of this concept is that drivers learn to make better judgments based on experience with the TCD, the research design must include a familiarization phase and an evaluation phase. Research participants should be exposed to approaching vehicles at a range of sites with the TCD, and given adequate experience. The evaluation of benefits (vs. no marking control) then needs to be done at other sites (transfer of benefits). The experimental research should include a range of different types of vehicles and approach speeds. Measures of effectiveness should include both the accuracy of perceptual judgments and the appropriateness of go/no go decisions for motorists crossing or turning onto the primary road. Studies should also examine the awareness of approaching drivers and their ability to avoid conflicts at the intersection.

4. Implement the most effective treatment in a field test. In order to be meaningful, the field implementation must be implemented system-wide and for an extended period. A cooperating jurisdiction should be part of the research team from the onset of the project. Benefits should be assessed in terms of reductions in conflicts at intersections and in terms of collision experience.

5. Define the benefits of the TCD in terms of collision reduction. Conduct a benefit/cost analysis.

6. Provide detailed TCD design specifications, recommendations for implementation, and warrants for use.

\section{Keywords:}

Intersections

Turns

Time to contact

Gap acceptance

\section{Cost/Time:}

$\$ 900 \mathrm{~K}$ over 5 years.

\section{Implementation:}

Findings should be disseminated to appropriate AASHTO and TRB committees and to state and local traffic agencies. New TCDs or applications should be submitted to the National Committee on Uniform Traffic Control Devices for consideration as standards for this application.

\section{Potential Benefits:}

This device should reduce serious angle collisions at unsignalized intersections. It may also be applicable at signalized intersections where right-turn-on-red is permitted. 


\section{Conflicting Vehicle Warnings at Non-signalized Intersections}

\section{Problem:}

Intersections represent areas of high accident concentration and frequency. In many jurisdictions, the majority of all accidents are intersection occurrences. A likely causal factor contributing to this problem in rural areas is that drivers frequently err in their estimation of the time required to turn onto undivided rural roads and attain prevailing traffic speed. In the laboratory research portion of this project (Lerner, Steinberg, Huey, \& Hanscom, 1998), these driver judgmental problems were observed for both high-speed and low-speed roadways, though more pronounced for the higher speed roads. Such misjudgment could lead to the acceptance of inadequate gaps for vehicles turning onto the primary roadway.

There have been efforts to develop intelligent sign systems to warn drivers about potential vehicle conflicts at intersections. Recent and ongoing ITS intersection collision-reduction efforts, sponsored by the Federal Highway Administration (e.g., Ratheon, Inc., 1994) and the State of Oregon (K. J. Haas, personal communication, March 19, 1999), have designed and operated activated signing and pavement loop systems to warn of approaching traffic at rural intersections with limited sight distance. These devices provide LED or bulb matrix icons that notify drivers of traffic presence on the intersecting leg. A driver stopped on the minor approach receives a message indicating that there is an approaching vehicle and indicating whether it is from the left or right. The driver approaching on the primary road receives a message that there is a vehicle at the cross road. Preliminary tests of the system in Virginia have shown promise, and additional evaluations are on-going. However, in its current form, the system does not directly address the driver misperceptions identified by Lerner et al. (1998). The system helps the driver recognize a potential conflict, but it does not address the judgment of the adequacy of the gap. Furthermore, the warning may lack credibility because it is not sensitive to the actual degree of hazard. The warning is simply based on the presence of an approaching vehicle within a designated section of the highway, but does not take the speed of the vehicle into account. Therefore, the warning is not sensitive to the actual gap available, so drivers may tend to dismiss the information as too conservative in many cases.

There is a need to refine rural intersection warning systems to address the misperceptions of drivers and provide a better aid to decision making. Design modifications to current systems are required to: (1) identify vehicle-specific location and speed requirements for detected vehicles on the instrumented roadway to avoid potential right-angle collisions, and (2) assist a turning vehicle driver in decisions to proceed based on specific gap acceptance criteria.

\section{Objective:}

The purpose of the project is to refine rural intersection intelligent warning systems to provide a more effective TCD to aid turning drivers. In order to accomplish this, the project will need to: (1) determine the criteria for when to present a warning; and (2) determine what additional information should be provided to the driver to improve decision making.

\section{Scope:}

The focus is on intersections on higher speed rural roadways, and must consider a range of applications to include a variety of intersection geometric conditions, e.g., intersection width, corner sight distance, operating speed, approach grade; and vehicle factors, e.g., type, length, 
outlier speed characteristics. Effectiveness for both day and night applications is required. The systems of interest are those that aid the driver in perception and decision regarding gaps, but do not actually control vehicle movements (i.e., do not provide "stop" or "go" messages).

\section{Anticipated Tasks/Methodology:}

1. Review relevant research and practice. This includes engineering criteria and research studies that pertain to intersection sight distance criteria, driver gap acceptance, perception of vehicle speed/distance, and turning maneuvers. Critically review past and current efforts to develop active intersection and/or gap warning systems or decision aids. Contact experts experienced with related efforts to get information on concepts based on current research and operational experience.

2. Define study parameters: i.e., (1) roadway situations of interest, e.g., intersection width, approach operating speed; and (2) perceptual and traffic engineering factors relevant to the tested intersection crossing/turning traffic control aid, prior icon/symbol application; (3) visibility of tested icon/symbol, ambient (lighting, weather) effects on visibility; (4) field of view, approach visibility time; (5) fail-safe requirements, liability implications, etc. Prioritize candidate study conditions for experimental application.

3. Conduct a detailed behavioral task analysis of driver use of targeted intersection conditions (e.g., sight distances, approach speeds) with particular attention to information needs, driver expectancy, and error potential.

4. Identify alternative traffic control concepts and specific candidate devices to aid motorists with their recognition of appropriate gaps for safe intersection crossing/turning. This includes: (a) alternative algorithms for triggering a warning; (b) alternative information types that can be provided to drivers (e.g., presence of a vehicle, time to arrival, speed or distance, level of warning); (c) alternative means of encoding the message (text, icons, count-downs, etc.); and (d) alternative means for displaying the message (display type, e.g. LED, display location).

5. Conduct a laboratory evaluation of alternative intersection crossing/turning TCD/icon aids and alternative strategies for operational aspects. Evaluation should include driver comprehension of TCDs, driver awareness of operational conditions, and appropriateness of driver decision making with regard to crossing/turning maneuvers.

6. Evaluate driver response to the promising candidate treatment set in a test track or closed course setting.

7. Conduct a benefit/cost evaluation of the most promising treatment(s) and select the candidate(s) to carry forward to field testing.

8. Implement the most effective treatment(s) in a field test. The field test must be of sufficient duration that local drivers are familiar with the system and perceptions of validity, and driver decision making, become stable.

9. Based on the findings, develop recommendations for intersection cross/turning aids. Include warrants for use, operational and design factors, and TCD requirements.

10. Document the findings and recommendations in a final report. 


\section{Keywords:}

Intersections

Turns

Gap acceptance

Non-signalized intersection accidents

Intersection collision avoidance systems

\section{Cost/Time :}

$\$ 900 \mathrm{~K}$ over 4 years

\section{Implementation:}

Findings should be disseminated to state highway administrations, AASHTO, ITS America, and TRB. Efforts should be made to have these groups provide advocacy for the concept and encourage funding of wider field evaluation. After broader testing and acceptance, the TCDs should be submitted to the National Committee on Uniform Traffic Control Devices for consideration as standards.

\section{Potential Benefits :}

The treatment should reduce the likelihood of severe angle crashes at higher speed rural intersections. 


\section{High Speed Approaching Vehicle Warnings at Intersections}

\section{Problem:}

In the laboratory study portion of this project (Lerner, Steinberg, Huey, and Hanscom, 1998), participants made errors in judgments of left or right turns from a stop onto higher-speed roadways. The majority of participants underestimated the time available for a vehicle coming from the right or left to reach their location, but 12 to 38 percent overestimated this judgment, and some erred very substantially ( 2 to $3 \mathrm{sec}$ ). When judgments of the arrival time of an approaching vehicle and judgments of time to attain prevailing speed after the turn were considered jointly, the large majority of participants ( $>90$ percent) had net safety-negative combined estimates. This type of error would result in potential conflicts with approaching vehicles, causing them to slow down in order to avoid a collision. In addition to the threat of collision with the subject vehicle, this could also result in conflicts with vehicles following the initial approaching vehicle. The Lerner et al. (1998) study did not vary the approach speed of vehicles, but an expert panel convened to interpret the findings felt that outlier speeds were most likely to be misjudged. While many such conflicts may be avoided by the conflicting vehicle slowing down or changing lanes, a greater risk may exist for the relatively rare instance of a conflicting vehicle travelling at unusually high speed, where there may be insufficient time for that vehicle to slow down or otherwise make an avoidance maneuver.

\section{Objective:}

This project will investigate the effectiveness of an active warning at unsignalized intersections when a speeding vehicle is approaching at substantially higher than normal speed. Examples of such a warning may be a post-mounted indication of the oncoming vehicle's speed, seconds to arrival, a message such as "caution, vehicle approaching from right," or simply a warning light.

\section{Scope:}

The project should address the effectiveness of the warnings for a range of unsignalized intersections that vary in terms of site geometry, number of lanes, posted speed, sight distance, or other sites factors found to be related to the target accident type. Effectiveness for day and night application should be considered. The research should include a range of approaching vehicle types (automobile, trucks, motorcycles, etc.). The TCDs considered should include a range of active warning display alternatives (iconic, text, mounting locations). However, it should be limited to roadside visual warnings, not in-vehicle displays or acoustic signals.

\section{Anticipated Tasks/Methodology:}

1. Identify type(s) of roadways where intersection crashes involving conflicts between turning vehicles and vehicles travelling at higher than normal speed occur most frequently, using accident databases, available studies, or other sources. Characterize crashes and sites according to site features, environmental conditions, and driver behavior. Conduct field visits to a set of problem sites, and describe the speed characteristics of traffic and the related behavior of entering or crossing traffic. Based on these observations, provide a preliminary definition of what constitutes an "outlier" speed that may require driver warning. 
2. Conduct laboratory or controlled field experiments to understand driver misjudgments of speed, gap, and maneuver decisions as related to approach vehicle speed variations at intersections. Representative sites and conditions should be included, based on the previous task. The study should include an appropriate range of speeds for a given site, including high-speed outliers. The study should include a range of approaching vehicle types and speeds, direction and angle of approach, sight distance, visual complexity, and roadway characteristics.

3. Based on driver misperceptions and decision errors, define the conditions under which a high-speed approaching vehicle warning may be warranted. Develop decision algorithms upon which a warning system could be based.

4. Develop alternatives for the design and placement of TCDs for this application. Consider the format and content of warning images and messages. Conduct focus groups to consider comprehension, confusions, and improvements. Based on this, define a set of treatments for evaluation in the experimental study.

5. Conduct a laboratory or controlled field experiment, similar to that conducted previously, but with the objective of comparing alternative TCD treatments. TCD options should be compared with each other, and with the no-warning control condition, in terms of driver perceptions and judgments about the appropriateness of go/no go maneuver decisions.

6. Field evaluate the most promising alternative(s) at several sites with distinctly different characteristics. The evaluation should be based upon measures of effectiveness related to conflicts with entering or crossing vehicles, such as collisions, conflicts, gap acceptance distributions, speed distributions, etc.

7. Develop guidelines, warrants for use, and design specifications for recommended TCDs.

8. Document the methods, findings, and recommendations in a final report.

\section{Keywords:}

Intersections

Turns

Gap acceptance

Speeding

Active warnings

\section{Cost/Time:}

$\$ 750,000$ over 3 years

\section{Implementation:}

Findings should be disseminated to appropriate AASHTO and TRB committees and to state and local traffic agencies. New TCDs or applications should be submitted to the National Committee on Uniform Traffic Control Devices for consideration as standards for this application.

\section{Potential Benefits:}

This device should reduce serious angle collisions at unsignalized intersections. If may also be applicable at signalized intersections where right-turn-on-red is permitted. 


\subsection{References}

COMSIS Corporation \& TRC (1996). Determine causes of driver maneuver error: Literature review. Interim report under contract DTFH61-96-C-00015. Washington, DC: Federal Highway Administration.

Hancock, P.A. \& Manser, M.P. (1988). Time-to-contact. In A. Feyer \& A. Williamson. (Eds). Occupational injury: Risk perception intervention. London: Taylor and Francis, 44-58.

Institute of Traffic Engineers. (1994). Determining vehicle signal change and clearance intervals. Technical Council Task Force 4TF-1.

Lerner, N., Benel, D., \& Dekker, D. (1995). Understanding driver performance variability and perception of risk. Final report under contract DTFH 61-92-R-00107. Washington, DC: Federal Highway Administration.

Lerner, N. D., Benel, D. C. R., Huey, R. W., Hanscom, F., \& Steinberg, G. V. (1996). Driver maneuver errors research plan. Interim report under contract DTFH61-96-C-00015. Washington, DC: Federal Highway Administration.

Lerner, N. D., Steinberg, G. V., Huey, R. W., \& Hanscom, F. (1998). Determine causes of driver maneuver errors: Research findings. Draft report under contract DTFH61-96-C-00015. Washington, DC: Federal Highway Administration.

McKelvey, F. \& Stamatiadis, N. (1987). Accidents and the older driver at signalized and nonsignalized intersections. East-Lansing, MI: Michigan State University, College of Engineering.

Michaels, R. M. \& Fazio, J. (1989). Driver behavior model of merging. Transportation Research Record 1213, 4-10.

Newton, C. Mussa, R., Sadalla, E. Burns, E., \& Mathias, J. (1997). Evaluation of an alternative traffic light change system. Accident Analysis and Prevention, 29(2), 201-209.

Ratheon, Inc. (1994). Collision Countermeasures System (CCS) for an unsignalized intersection. Draft report submitted under contract DTFH61-94-C-00131. Washington, DC: Federal Highway Administration. 


\section{APPENDIX A. EXPERT PANEL ATTENDEES}

$\underline{\text { Invited Experts }}$

Gerson Alexander, Positive Guidance Applications, Inc.

Mark Freedman, Westat

Richard Huey, Westat

Robert Llaneras, Westat

Richard Pain, Transportation Research Board

Martin Pietrucha, Pennsylvania State University

Loren Staplin, The Scientex Corporation

$\underline{\text { Project Staff }}$

Fred Hanscom, TRC

Neil Lerner, Westat

Geoffrey Steinberg, Westat

Kathryn Woerheide, SAIC (representing FHWA project management) 